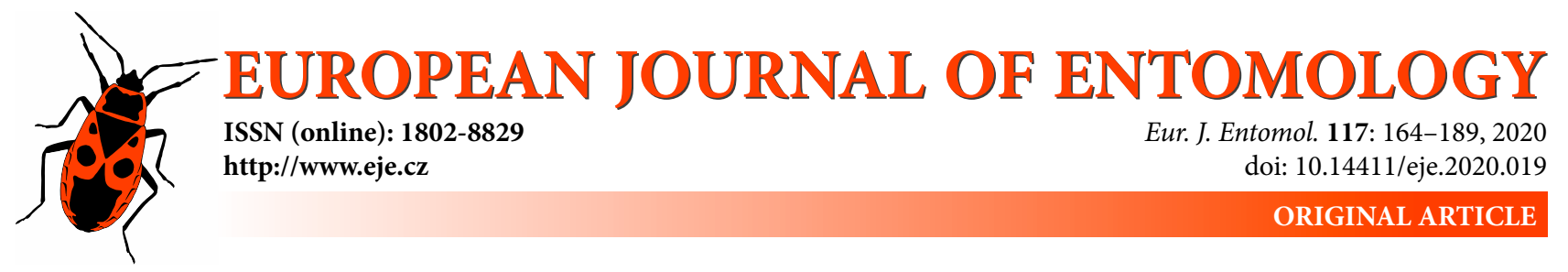

\title{
A revision of the Neotropical genus Chespiritos (Diptera: Sphaeroceridae: Limosininae)
}

\author{
Gregory K. KUWAHARA and Stephen A. MARSHALL
}

School of Environmental Sciences, University of Guelph, Guelph, Ontario, Canada N1G 2W1; e-mails: gkuwahar@uoguelph.ca, samarsha@uoguelph.ca

Key words. Diptera, Sphaeroceridae, Limosininae, Chespiritos, taxonomy, new species, Neotropics, comparative morphology

\begin{abstract}
The genus Chespiritos Marshall, 2000 (Diptera: Sphaeroceridae) is revised, including C. sindecimus Marshall, 2000 , C. pervadens Roháček and Buck, 2003 and 19 new species. The following new species are described, keyed and placed in a morphological phylogeny: C. anguineus sp. n. from Bolivia, C. attenboroughi sp. n. from Argentina, C. balrogiformis sp. n. from Peru, C. bolanosi sp. n. from Mexico, C. calceus sp. n. from Peru, C. chicobrazos sp. n. from Costa Rica, C. coronatus sp. n. from Bolivia, Brazil, Colombia, Costa Rica, Ecuador and Trinidad, C. dolabratus sp. n. from Costa Rica, C. elephantus sp. n. from Ecuador and Peru, C. extendido sp. n. from Bolivia, Colombia, Costa Rica, Ecuador, Mexico, Panama and Venezuela, C. ganchopico sp. n. from Argentina, Bolivia, Ecuador, Panama and Tobago, C. gladiator sp. n. from Costa Rica, C. hojagrande sp. n. from Costa Rica and Mexico, C. jamaicensis sp. n. from Jamaica, C. lepustergum sp. n. from Costa Rica and Venezuela, C. metroidiformis sp. n. from Costa Rica, C. paraiso sp. n. from Dominican Republic, C. peckorum sp. n. from Ecuador, and C. ventrisetis sp. n. from Brazil, Costa Rica and Venezuela.
\end{abstract}

ZooBank Article Registration: http://zoobank.org/urn:Isid:zoobank.org:pub:80DCB50F-37BD-4164-8D51-80B05FEC7428

\section{INTRODUCTION}

Chespiritos Marshall, 2000 is unique among sphaerocerid genera for the combination of a broad head, bulging lunule, three pairs of interfrontal setae (one small and two large), and six marginal scutellar setae (four large setae and two smaller basal setulae). This genus is further characterized by the presence of two pairs of dorsocentral setae, a costa that extends far beyond $\mathrm{R}_{4+5}$, and the unusual complete absence of the female epiproct (tergite 10). There are currently two described species of Chespiritos, C. sindecimus Marshall, 2000 from Costa Rica and $C$. pervadens Roháček \& Buck, 2003 from Brazil and the Canary Islands. The genus is mostly neotropical, ranging from southern Mexico to northern Argentina at elevations from sea level to $2100 \mathrm{~m}$ although most records are from above $800 \mathrm{~m}$. We here revise the genus with the description of 19 new Neotropical species, of which eight are known only from Central America, six are known only from South America, and five are known from both regions.

Little is known of the natural history of Chespiritos, though species are generally associated with decaying plant material. For example, Chespiritos ganchopico sp. n. has been reared and collected from Heliconia Linnaeus, 1771 (Heliconiaceae) in Ecuador and Panama and specimens of C. sindecimus were originally collected from bromeliads knocked down to the ground during storms in Costa Rica (Marshall, 2000). Most of the available specimens were collected using Malaise traps or pan traps located near or amongst decaying vegetation. A few specimens are from dung or carrion traps but, unlike most adult sphaerocerids, Chespiritos adults are not routinely attracted to dung and carrion. Furthermore, C. ventrisetis sp. n. has been collected from the heaps of regurgitated fruit and guano that cover the floors of caves inhabited by oilbirds, Steatornis caripensis Humboldt, 1814 within the Guacharo caves of Venezuela; these birds create nests out of regurgitated fruit and seeds, as well as excrement (Risco et al., 2011). While this species has been collected outside caves at other locations, its abundance and dominant presence deep in the Guacharo caves is of interest and significance. The development of Chespiritos ventrisetis around oilbird nests and associated refuse is consistent with the general association of this genus with decaying vegetation.

\section{MATERIALS AND METHODS}

Morphological terminology follows Cumming \& Wood (2009), with the addition of the term "medial connecting sclerite" used here to refer to an elongated sclerite connecting the posteromedial part of sternite 5 to synsternite $6+7$ ventromedially (as can be seen in Fig. 8.1). Marshall (2000) referred to this structure as a posteromedial lobe of sternite 5, but in all species of Chespiritos 
with this sclerite it is distinctly separated from and oriented perpendicular to sternite 5 . We therefore refer to it here as a separate sclerite.

Abbreviations include $\mathrm{S}$ - sternite(s); $\mathrm{T}$ - tergite(s). Label data are given in a standardized format rather than given verbatim from labels.

Male terminalia were prepared by soaking entire abdomens in room temperature $10 \%$ potassium hydroxide for five minutes prior to heating the potassium hydroxide to boiling point for 15-30 min. Cleared abdomens were subsequently neutralized in glacial acetic acid for at least $30 \mathrm{~min}$, then rinsed with deionized water and placed in glycerin for examination. All dissected parts of the specimens were stored in glycerin in genitalia vials pinned below the specimens.

Illustrations were created via free-hand drawings made while viewing specimens through a Leica Wild M3Z stereo microscope or a Nikon Labophot compound microscope. The illustrations were then compiled and edited using Photoshop Elements 9 (Adobe Services, CA, USA).

Measurements were taken from ten specimens of common species or all specimens from rarer species, from a variety of locations when possible. Measurements are approximate because dried specimens are subject to varying degrees of shrinkage and distortion. Body length measurements were taken from the tip of the head (lunule) to the tip of the abdomen.

The character matrix (Table 1) was created using Mesquite version 3.6 (Maddison \& Maddison, 2018) and analyzed using TNT version 1.5 (Goloboff \& Catalano, 2016). The phylogenetic tree (Fig. 27) was generated using Winclada (Nixon, 2002) and visually enhanced with Photoshop.

Acronyms of depositories. Specimens are deposited in the following institutions: BMNH - Natural History Museum (formerly British Museum of Natural History), London, UK; CBFC - Colección Boliviana de Fauna, La Paz, Bolivia; CNCI - Canadian National Collection of Insects, Arachnids and Nematodes, Ottawa, Ontario, Canada; DEBU - School of Environmental Sciences, University of Guelph, Guelph, Ontario, Canada; FMNH
- Field Museum of Natural History, Chicago, Illinois, USA; LACM - Los Angeles County Museum, Los Angeles, California, USA; MIZA - Museo del Instituto de Zoología Agrícola, Maracay, Venezuela; MNCR - Museo Nacional de Costa Rica, San José, Costa Rica; MUSM - Museo de Historia Natural, Universidad Nacional Mayor de San Marcos, Lima, Peru; MZSP - Museu de Zoologia, Universidade de São Paulo, Brazil; QCAZ - Museo de Zoología, Pontifica Universidad Catolica del Ecuador, Quito, Ecuador; USNM - United States National Museum of Natural History, Smithsonian Institution, Washington, District of Columbia, USA.

\section{TAXONOMY}

\section{Similar genera and relationships}

Marshall (2000) suggested Sclerocoelus Marshall, 1995 as a possible sister group to Chespiritos on the basis of the shared broad lunule and similar small setae in the intra-alar or posterior supra-alar position. Roháček \& Buck (2003) disputed the latter character as a possible generic synapomorphy, but genitalia of these genera provide some evidence for a close relationship between Sclerocoelus and Chespiritos. The probable ground plan condition of the surstylus in Chespiritos, as reflected in the basal Chespiritos species $C$. jamaicensis sp. n. and C. calceus sp. n., is similar to that found in Sclerocoelus. Both groups have distinctive ventromedially cleft surstyli as illustrated for Sclerocoelus hemorrhoidalis Marshall, 1997 and S. brasilensis Marshall, 1997 in Marshall (1997). We therefore root our phylogenetic analysis of Chespiritos with Sclerocoelus (represented in the matrix by $S$. hemorrhoidalis plus $S$. brasilensis) as the outgroup.

Pullimosina (Dahlimosina) darwini Richards, 1931 is superficially similar to most Chespiritos in having a small pair of basal scutellar setulae, the costa extending well past

Table 1. Character state matrix for Neotropical species of Chespiritos, including two species of Sclerocoelus as the outgroup. Plesiomorphic states are indicated by $(0)$ and apomorphic state(s) by (1-2). Multistate characters are treated as unordered.

\begin{tabular}{|c|c|c|c|c|c|c|c|c|c|c|c|c|c|c|c|c|c|c|c|c|c|c|c|c|c|c|c|c|}
\hline \multirow{2}{*}{ Taxon } & \multicolumn{28}{|c|}{ Characters } \\
\hline & 01 & 02 & 03 & 04 & 05 & 06 & 07 & 08 & 09 & 10 & 11 & 12 & 13 & 14 & 15 & 16 & 17 & 18 & 19 & 20 & 21 & 22 & 23 & 24 & 25 & 26 & 27 & 28 \\
\hline Sclerocoelus brasilensis & 0 & 2 & 0 & 0 & 0 & 0 & 0 & 0 & 0 & 0 & 0 & 0 & 0 & 0 & 0 & 0 & 0 & 0 & 0 & 0 & $?$ & 0 & $?$ & $?$ & $?$ & 0 & 0 & 0 \\
\hline clerocoelus hemorrhoidalis & 0 & 0 & 0 & 0 & 0 & 0 & 1 & 0 & 0 & 0 & 0 & 1 & 0 & 0 & 0 & 0 & 0 & 0 & 0 & 0 & $?$ & 0 & 0 & $?$ & $?$ & 0 & 0 & 0 \\
\hline hespiritos calceus & 0 & 0 & 1 & 0 & 0 & 1 & 0 & 0 & 0 & 0 & 0 & 1 & 1 & 0 & 0 & 0 & 1 & 0 & $?$ & 1 & $?$ & $?$ & $?$ & $?$ & $?$ & $?$ & $?$ & $?$ \\
\hline Chespiritos metroidiformis & 1 & 0 & 0 & 0 & 0 & 1 & 0 & 0 & 0 & 0 & 1 & 1 & 1 & 0 & 0 & 0 & 0 & 1 & 1 & 1 & $?$ & $?$ & $?$ & $?$ & $?$ & $?$ & $?$ & $?$ \\
\hline Chespiritos jamaicensis & 1 & 1 & 0 & 0 & 0 & 1 & 0 & 0 & 0 & 0 & 0 & 0 & 1 & 0 & 0 & 0 & 0 & 2 & 1 & 1 & 2 & 0 & 1 & 0 & 0 & 1 & 1 & 1 \\
\hline hespiritos elephantus & 1 & 1 & 1 & 1 & 1 & 1 & 0 & 1 & 0 & 0 & 1 & 0 & 1 & 1 & 0 & 0 & 0 & 2 & 1 & 2 & $?$ & $?$ & $?$ & $?$ & $?$ & $?$ & $?$ & $?$ \\
\hline Ches & 1 & 1 & 1 & 1 & 1 & 1 & 0 & 1 & 0 & 0 & 1 & 0 & 1 & 1 & 0 & 0 & 0 & 1 & 1 & 2 & 2 & 0 & $?$ & 1 & 1 & 0 & 0 & 0 \\
\hline Chespiritos chicobrazos & 1 & 0 & 1 & 0 & 1 & 2 & 0 & 0 & 1 & 0 & 1 & 0 & 0 & 1 & 0 & 0 & 0 & 0 & $?$ & 1 & 0 & 1 & 0 & 1 & 1 & 1 & 0 & 1 \\
\hline adiator & 1 & 0 & 1 & 1 & 1 & 1 & 0 & 1 & 0 & 0 & 1 & 0 & 1 & 1 & 0 & 0 & 0 & 1 & 1 & 2 & 0 & 1 & 1 & 1 & 1 & 1 & 0 & 1 \\
\hline iform & 1 & 1 & 1 & 0 & 0 & 2 & 0 & 1 & 0 & 0 & 1 & 0 & 1 & 0 & 0 & 1 & 1 & 1 & 1 & 1 & $?$ & $?$ & $?$ & $?$ & $?$ & $?$ & $?$ & $?$ \\
\hline Chespiritos & 1 & 1 & 1 & 0 & 0 & 2 & 0 & 1 & 1 & 0 & 1 & 0 & 1 & 0 & 0 & 1 & 1 & 2 & 1 & 1 & $?$ & $?$ & $?$ & $?$ & $?$ & $?$ & $?$ & $?$ \\
\hline & 1 & 2 & 1 & 0 & 0 & 2 & 0 & 1 & 1 & 0 & 1 & 0 & 1 & 0 & 0 & 0 & 0 & 2 & 1 & 1 & 0 & 1 & 2 & 0 & 1 & 0 & 1 & 0 \\
\hline Chespiritos & 1 & 2 & 1 & 0 & 0 & 2 & 1 & 1 & 1 & 0 & 1 & 0 & 1 & 0 & 0 & 0 & 1 & 1 & $?$ & 1 & 1 & 1 & 0 & 0 & 1 & 1 & 0 & 1 \\
\hline Chespiritos & 1 & 1 & 1 & 0 & 0 & 1 & 0 & 0 & 0 & 0 & 2 & 0 & 1 & 0 & 1 & 1 & 1 & 2 & 1 & 1 & $?$ & $?$ & $?$ & $?$ & $?$ & $?$ & $?$ & $?$ \\
\hline Che & 1 & 1 & 1 & 0 & 0 & 1 & 1 & 0 & 0 & 1 & 1 & 1 & 1 & 0 & 1 & 1 & 1 & 2 & 1 & 1 & 1 & 1 & 1 & 0 & 1 & 0 & 0 & 1 \\
\hline Chespiritos hojag & 1 & 1 & 1 & 0 & 0 & 1 & 1 & 0 & 0 & 1 & 2 & 1 & 1 & 0 & 1 & 1 & 1 & 2 & 1 & 1 & $?$ & $?$ & $?$ & $?$ & $?$ & $?$ & $?$ & $?$ \\
\hline Chespiritos coronatus & 1 & 1 & 1 & 0 & 0 & 1 & 1 & 0 & 0 & 1 & 2 & 1 & 0 & 0 & 1 & 1 & 1 & 2 & 1 & 1 & 1 & 1 & 1 & 0 & 1 & 0 & 0 & 1 \\
\hline Chespiritos lepu & 1 & 1 & 1 & 0 & 0 & 1 & 1 & 0 & 0 & 1 & 2 & 1 & 0 & 0 & 1 & 1 & 1 & 2 & 1 & 1 & 1 & 1 & 0 & 0 & 1 & 0 & 0 & 1 \\
\hline Chespiritos ganchopico & 1 & 2 & 1 & 0 & 0 & 1 & 0 & 0 & 0 & 1 & 1 & 0 & 1 & 0 & 1 & 1 & 1 & 2 & 2 & 1 & 1 & 1 & 0 & 1 & 1 & 1 & 0 & 1 \\
\hline Chespiritos extendido & 1 & 2 & 1 & 0 & 0 & 1 & 0 & 0 & 0 & 1 & 1 & 0 & 1 & 0 & 1 & 1 & 1 & 2 & 2 & 1 & 2 & 1 & 2 & 0 & 0 & 0 & 0 & 1 \\
\hline Chespiritos paraiso & 1 & 0 & 1 & 0 & 0 & 2 & 0 & 0 & 0 & 1 & 1 & 1 & 1 & 0 & 1 & 1 & 1 & 2 & 2 & 1 & 1 & 1 & 0 & 0 & 1 & 1 & 1 & 1 \\
\hline Chespiritos bolanosi & 1 & 0 & 1 & 0 & 0 & 2 & 0 & 0 & 0 & 1 & 1 & 1 & 1 & 0 & 1 & 1 & 1 & 2 & 2 & 1 & 2 & 1 & 1 & 0 & 1 & 1 & 1 & 1 \\
\hline Chespiritos dolabratus & 1 & 0 & 1 & 0 & 0 & 2 & 0 & 0 & 0 & 1 & 1 & 1 & 1 & 0 & 1 & 1 & 1 & 2 & 2 & 1 & 2 & 1 & 2 & 0 & 1 & 0 & 1 & 1 \\
\hline
\end{tabular}


$\mathrm{R}_{4+5}$, and mid tibial chaetotaxy with anterodorsal and posterodorsal proximal setae and a set of four distal setae. Pullimosina (Dahlimosina) darwini can, however, be easily distinguished from Chespiritos by the presence of a broad alula, three well-developed postsutural dorsocentral setae, and a narrower lunule.

\section{Character state matrix}

The plesiomorphic state is indicated by $(0)$ and the apomorphic state(s) by (1-2). Multistate characters are treated as unordered.

1. Basal scutellar setulae: (0) absent; (1) present.

2. Mid femur: (0) with three ventral setae; (1) with four ventral setae; (2) with five ventral setae.

3. Male S5 medial length: (0) $0.33-0.50 \times$ width; $(1)<0.33 \times$ width.

4. Male S5: (0) without posterior brush of setae; (1) with posterior brush of setae.

5. Male S5, anterior lobe(s): (0) absent; (1) present.

6. Male S5, posterolateral lobes: (0) absent; (1) shorter than or equal to medial length; (2) longer than medial length.

7. Male S5, posteromedial lobes: (0) absent; (1) present.

8. Surstylus, width: $(0)$ broad, $>0.5 \times$ epandrial length; (1) narrow, $<0.5 \times$ epandrial length.

9. Surstylus: (0) distal half not bent posteriorly; (1) distal half bent posteriorly.

10. Surstylus: (0) without stout anterior setae; (1) with stout anterior setae.

11. Surstylus, length: (0) $0.25 \times$ epandrial height; (1) 0.33 $0.75 \times$ epandrial height; (2) $1.0 \times$ epandrial height.

12. Postgonite, apical third: (0) narrower or equal to basal third; (1) broader than basal third.

13. Postgonite: (0) straight; (1) curved anteriorly or sinuate.

14. Postgonite: (0) without tooth-like posterior lobe; (1) with tooth-like posterior lobe.

15. Distiphallus: (0) with one or two broad distal lobes; (1) with three narrow distal lobes.

16. Distiphallus: (0) apical half mostly membranous; (1) apical half sclerotized.

17. Distiphallus, apex: (0) without reticulated pattern; (1) with reticulated pattern.

18. Medial connecting sclerite: (0) absent; (1) present but hidden behind medial portion of S5 in ventral view; (2) present and visible, not hidden behind medial portion of S5 in ventral view.

19. Medial connecting sclerite: (0) absent; (1) short and stout; (2) long and thin.

20. Posteromedial arms of hypandrial fork: (0) absent; (1) short; (2) long.

21. Female T7 width: (0) $1.0 \times$ T3 width; (1) $1.25 \times$ T3 width; (2) $1.50-2.0 \times \mathrm{T} 3$ width.

22. Female T7 anterolateral lobe: (0) absent; (1) present.

23. Female T7 posteromedial notch width: (0) $0.12-0.20 \times \mathrm{T} 7$ width; (1) $0.25 \times \mathrm{T} 7$ width; (2) $0.33-0.50 \times \mathrm{T} 7$ width.

24. Female T8 anterolateral lobes: (0) connected to T8; (1) separated from $\mathrm{T} 8$.

25. Female T8 posterolateral lobes: $(0)$ connected to T8; (1) separated from $\mathrm{T} 8$.

26. Spermathecae: (0) bulb stout, spherical; (1) bulb elongate, cylindrical.

27. Spermathecae: (0) bulb grooved; (1) bulb smooth.

28. Spermathecae: (0) with apical invagination; (1) without apical invagination.
Two equally parsimonious trees (length 87 , consistency index 0.41 , retention index 0.66 ), differ only in the relationships between three small groups: the $C$. sindecimus group, $C$. ganchopico and $C$. extendido, and the $C$. dolabratus group. The preferred tree (Fig. 27) places the $C$. dolabratus species group as sister to $C$. ganchopico and $C$. extendido based on the unique synapomorphy of a long medial connecting sclerite (character 19)

The most strongly supported clade within Chespiritos is the $C$. ventrisetis species group. This group is characterized by the presence of large anterior lobes and a dense, posterior setal brush on the male fifth sternite (characters 4 $\& 5$, though $C$. chicobrazos sp. n. has a weak setal brush), postgonites with tooth-like posterior lobes originating from the basal third (character 14) and a hypandrium with long posteromedial arms (character 20). The C. ventrisetis group is distributed across Central and South America, with the widespread $C$. ventrisetis sp. n. found as far south as the southern Brazilian state of Santa Catarina. Chespiritos ventrisetis sp. n., C. chicobrazos sp. n. and C. gladiator sp. n. have all been collected from the Monteverde Biological Reserve in Costa Rica.

The $C$. sindecimus species group is characterized by the presence of posteromedial lobes on the male S5 (character 7) and large, leaf-like surstyli. The $C$. sindecimus group occurs from Mexico to southern Brazil, with $C$. coronatus having the largest known range in the group.

The $C$. dolabratus species group is characterized by a medially short male S5 with long posterolateral lobes (character 6) and distinctively shaped postgonites with the apical quarter constricted. Additionally, females of this group have paired spermathecae with smooth bulbs and a single spermatheca with a grooved bulb (character 27). The C. dolabratus group is known from Mexico, Costa Rica and the Dominican Republic, with each species recorded from only a single country.

\section{Distribution}

Most species are known from only one or two countries, but a few are more widespread and some, such as C. ganchopico sp. n., C. extendido sp. n., and C. coronatus sp. n., occur in both Central and South America. Chespiritos extendido sp. $\mathrm{n}$. is the only species currently known from the Galápagos Islands. Chespiritos pervadens, recorded from the Canary Islands as well as Brazil, is the only species of the genus known from outside the Neotropics; Roháček and Buck (2003) suggest that the species was introduced to the islands from South America. Costa Rica seems to have the highest diversity of species of Chespiritos, with 10 species, but the Costa Rican fauna has been more extensively sampled than that of other Neotropical countries. Typically, only one or two species of Chespiritos are collected from any given locality, but some locations in Costa Rica, such as the Monteverde Biological Reserve in Puntarenas and Pandora in Limón, have yielded several species.

C. extendido sp. n. and C. coronatus sp. n. are both found at an extremely wide range of elevations and in a variety of habitats, with $C$. extendido sp. n. having been collected at altitudes of $250 \mathrm{~m}$ to $2100 \mathrm{~m}$ above sea level, in habi- 
tats ranging from rainforests to cloud forests. Specimens have been taken in a variety of collection devices including dung traps, carrion traps, compost pan traps and Malaiseflight intercept traps. Chespiritos coronatus sp. $\mathrm{n}$. has been collected at elevations ranging from $160 \mathrm{~m}$ to $2000 \mathrm{~m}$. Unlike $C$. extendido sp. n. and $C$. coronatus sp. n., most $C h e-$ spiritos species are known from a single country, and often a single locality. Narrowly distributed species in the genus include $C$. jamaicensis sp. n. from Jamaica, C. balrogiformis sp. n. from Peru and C. attenboroughi sp. n. from Argentina.

\section{Genus Chespiritos Marshall, 2000}

Chespiritos Marshall, 2000: 609 (masculine); Roháček et al., 2001: 134 (catalogue); Roháček \& Buck, 2003: 43 (diagnosis); Marshall et al., 2011: 238 (catalogue).

Type species. Chespiritos sindecimus Marshall, 2000, original designation.

\section{Description}

Body length. Males 1.5-2.4 mm, females $1.2-2.9 \mathrm{~mm}$. Body colour ranging from very dark to very light brown; legs paler.

Head. Very broad, frontal width $\sim 3.0 \times$ interfrontal height. 2 pairs of large interfrontal setae preceded by 1 pair of smaller setae; 2 large lateroclinate orbital setae; ocellar setae large and diverging; postvertical and postocellar setae small; inner occipital seta large; vibrissa very large with two distinct subvibrissal setae. Clypeus large, dark and often exposed, lunule rounded and bulging. Palpus clavate, ventrally setose with a distinct preapical ventral seta. Orbital plate, interfrontal stripe and ocellar triangle with silver pollinosity. First flagellomere compressed; arista pubescent, dorsobasal, $\sim 2.0 \times$ height of head. Compound eye with shallow notch along anterior edge, posteroventral edge straight; eye height $\sim 2.0-2.5 \times$ genal height.

Thorax. Uniformly pruinose; 2 pairs of large postsutural dorsocentral setae, anterior pair separated by $6-8$ rows of acrostichal setae; posteromedial pair of acrostichal setae enlarged, $\sim 0.5 \times$ length of posterior dorsocentral seta; 2 postpronotal setae, outer seta large and inner seta small; 2 large notopleural setae, anterior pair slightly larger than posterior pair; 2 pairs of strong supra-alar setae; postalar and intrapostalar setae strong. Katepisternum with anterolateral pair of setae, posterior seta enlarged, and some smaller scattered lateral setae. Scutellum long, with 2 pairs of large marginal setae and 1 smaller basal pair of setulae.

Legs. Fore femur with 1 row of long ventral setae. Basal half of mid tibia with 6-8 dorsal setae including 2-3 small and 1 large anterodorsal setae, and 3-4 small posterodorsal setae above 1 at least slightly stouter posterodorsal seta. Distal half of mid tibia with 7 dorsal setae (2-3 anterodorsal, 2 dorsal and 2-3 posterodorsal). Mid tibia with large apicoventral and anteromedial setae, distal third of male mid tibia with two rows of stout setae ventrally; proximal quarter of mid femur with two rows of 3-5 corresponding ventral setae. Mid basitarsus with a prominent apicoventral seta. Mid coxa with three distinct lateral setae.
Wing. Elongate, $\sim 2.5 \times$ long as wide; third costal sector slightly shorter than second costal sector; costa basal to subcostal break with strong setae and a large costagial seta; $\mathrm{R}_{4+5}$ upcurved, meeting costa well before wing tip; costa extending far beyond $\mathrm{R}_{4+5}(\sim 7 \times$ costal width $)$; distance between crossveins dm-cu and $\mathrm{r}-\mathrm{m} \sim 2.0-3.0 \times$ the length of crossvein dm-cu; both $\mathrm{M}$ and $\mathrm{CuA}_{1}$ extending slightly beyond dm cell; alula narrow.

Male abdomen. S3-4 unmodified and well sclerotized. S6 and S7 expanded and fused dorsolaterally to form a genital pouch; left side of S6+7 wrapped underneath S5 and connected via the medial connecting sclerite, typically bearing two stout setae (Fig. 8); sclerite may not be visible in some species. Cerci typically rounded, pad-shaped and medially fused, with 1 or 2 larger setae and numerous smaller setulae. Hypandrium typically elongate and sinuate; cleft posteriorly with a set of forked arms: lateral arms extending to and continuous with ventrolateral corners of epandrium and posteromedial arms small, extending posteriorly to surround the anterior half of the distiphallus. Ejaculatory apodeme simple, S-shaped and largely desclerotized. Basiphallus stout and wedge-shaped, epiphallus often expanded and hooked giving the basiphallus an axeblade shape. Distiphallus in two distinct sections, a sclerotized and tubular proximal half, and a membranous distal half with some supporting sclerites. Phallapodeme long, dark and slightly sinuate with a pair of posterior lobes and a small ventral lobe just prior to the paired lobes; phallapodeme articulating with the basiphallus around these three lobes.

Female abdomen. Tergites uniformly setose with long posterolateral setae and a sparse posterior setal brush. T7 with a pale posteromedial notch and a small anterolateral lobe. T8 slightly desclerotized dorsomedially, with small anterolateral and posterolateral lobes; posterolateral lobe often slightly separated from main body of T8. Epiproct absent. Cercus short and tapered, with 3 small medial setae, 1 large apical seta and a smaller curved preapical dorsal seta. S3-7 uniformly setose with sparse posterior setal brush. S7 large and shield-like; S8 reduced to a pair of rounded plates normally mostly hidden by $\mathrm{S} 7$ in ventral view, each with a pair of setae. Vaginal sclerite semicircular with a distinct posteromedial process; hypoproct reduced to a pair of indistinct plates located just under the cerci. Spermathecae $(2+1)$ mushroom-shaped: apical section ovoid or spherical, basal section forming a conical stem connecting to the sclerotized distal parts of the spermathecal ducts; apical section of single spermatheca sometimes different in shape or texture from that of paired spermathecae. Pleural membrane uniformly setose.

\section{Key to species}

This key is based almost entirely on features of the male terminalia as most species are otherwise indistinguishable morphologically.

1 Scutellum with 4 marginal scutellar setae only, without additional marginal setulae (Peru)................... C. calceus sp. n. Scutellum with basal scutellar setulae in addition to the 4 marginal setae (Fig. 2.2) ...................................................... 2 


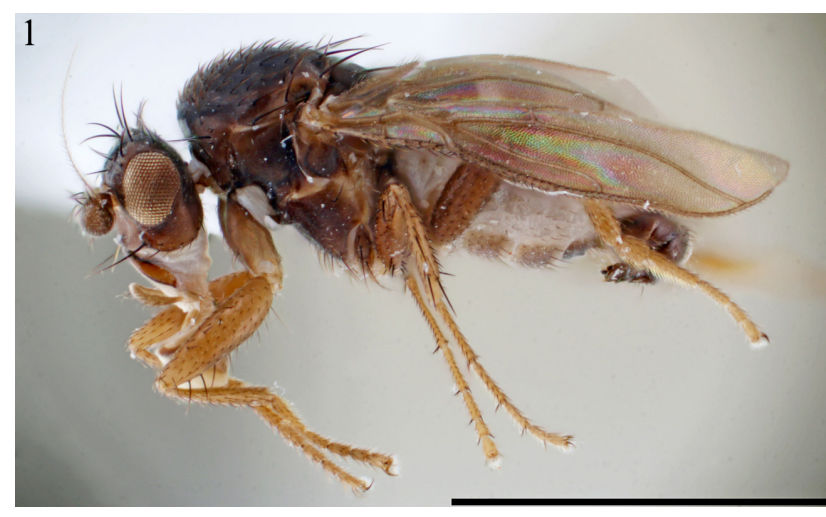

Fig. 1. Lateral habitus of male Ecuadorian Chespiritos extendido sp. n. paratype (debu00111716). Scale bar: $1.0 \mathrm{~mm}$.

2 Male S5 with posterolateral lobe longer than medial length of sternite (Figs 14.1, 15.1, 18.1, 23.1) ...................................... 3 Male S5 with at most a very short posterolateral lobe (Figs 8.1, 9.1, 10.1, 12.1) ........................................................ 14

3 Surstylus thin and L- or S-shaped (Figs 14.2, 15.2, 16.2) ... 4

- Surstylus broad and leaf-shaped (Figs 18.2, 19.2, 21.2, 22.2)

4 Posterolateral lobes of S5 curved inwards evenly with one distinctly flattened apical seta and dense lateral setae but without a dense patch of microtrichia apically (Fig. 14.1); surstylus L-shaped, bent $90^{\circ}$ posteriorly (Fig. 14.2); postgonite with a large, rectangular posterobasal lobe (Fig. 14.3); cercus with a large ventral lobe (Bolivia)...

..C. anguineus sp. $\mathrm{n}$.

- Posterolateral lobes of S5 straight to slightly curved, without a flattened apical seta, each lobe with a dense patch of microtrichia apically; surstylus bent posteriorly at an angle greater than $90^{\circ}$, thus sinuate in appearance; postgonite without a large rectangular posterobasal lobe; cercus evenly rounded along ventral surface, without a large lobe............................ 5

5 S5 with three small posteromedial lobes and a broad, longsetose posterolateral lobe (Fig. 16.1); cercus densely setose; surstylus straight along anterior edge, not sinuate; postgonite curved, not sinuate (Fig. 16.3); distiphallus apically reticulated (Argentina) .................................. . attenboroughi sp. n. S5 with thin, slightly sinuate, short-setose posterolateral lobe but without medial lobes (Fig. 15.1); cercus with sparse setation; surstylus sinuate; postgonite sinuate (Fig. 15.3); distiphallus apically grooved but not reticulated..

C. pervadens Roháček \& Buck, 2003 (Brazil, Canary Islands)

6 S5 with a pair of small posteromedial lobes (Figs 18.1, 19.1,

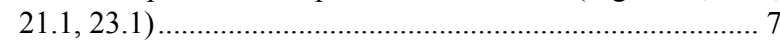

- S5 posteromedially unmodified, without a pair of small posteromedial lobes................................................................... 10

7 Space between posteromedial lobes of S5 small, $<0.20 \times$ width of S5; anterior edge of surstylus sinuate; postgonite with ventral edge flattened and ridged laterally, resembling a stamping press (Fig. 21.3a) (Costa Rica)

..C. lepustergum sp. $\mathrm{n}$.

Space between posteromedial lobes of S5 large, $>0.25 \times$ width of S5; anterior edge of surstylus evenly convex or only slightly sinuate; postgonite ventrally tapered, not flattened . 8

8 Surstylus with a large, triangular lateral lobe (Fig. 23.2a); medial lobes of S5 small, triangular; medial connecting sclerite elongate with apex swollen (Fig. 23.1) (widespread across Central and South America, including the Galapagos Islands). C. extendido sp. $\mathrm{n}$.

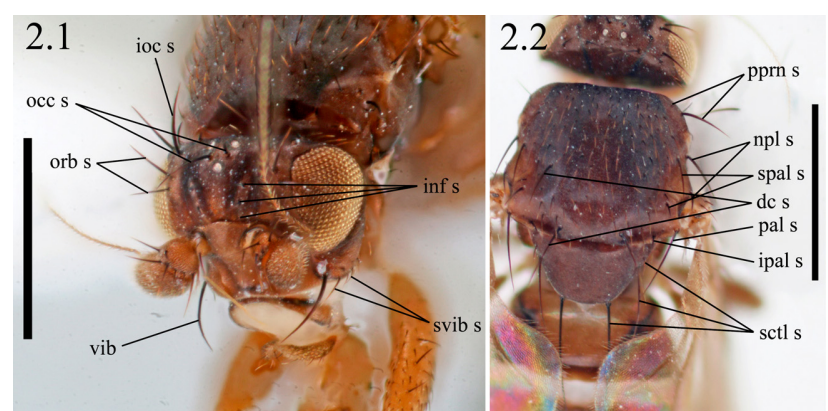

Figs 2.1-2.2. Head and thorax of male Ecuadorian Chespiritos extendido sp. n. paratype (debu00111716). 2.1 - head, anterolateral; 2.2 - thorax, dorsal. Abbreviations: dc s - dorsocentral setae, ioc s - inner occipital seta, inf s - interfrontal setae, ipal s - intrapostalar seta, $\mathrm{npl} \mathrm{s}$ - notopleural seta, occ s - ocellar setae, orb s - orbital setae, pal s - postalar seta, pprn s - postpronotal setae, sctl s - scutellar setae, svib s - subvibrissal setae, spal s - supra-alar seta, vib - vibrissa. Scale bars: $0.50 \mathrm{~mm}$.

- Surstylus with lateral surface smooth, without a large lobe; medial lobes of S5 large, rounded (Fig 18.1, 19.1); medial connecting sclerite stout, without apex swollen (Figs 18.1, 19.1)

9 Posterolateral lobes of S5 with many long setae (Fig. 19.1); main part of S5 with setulae; posteromedial lobes small and projecting posteriorly; medial connecting sclerite narrow; postgonite with a broadly emarginate apex (Fig. 19.3); surstylus triangular (Costa Rica, Mexico) ...C. hojagrande sp. n. Posterolateral lobes of S5 mostly bare but with a few long setae (Fig. 18.1); main part of S5 bare; posteromedial lobes long and slightly projecting medially; medial connecting sclerite broad; postgonite with a large rounded lobe apicodorsally (Fig. 18.3); surstylus rectangular (Costa Rica)

C. sindecimus Marshall, 2000

10 Postgonite abruptly narrowed in apical quarter, often creating a right angle on each side between the apicomedial process and the more basal section (Figs 24.3, 25.3, 26.3) ..............11 Postgonite gradually narrowed in apical quarter (Figs 17.3, 22.3)

11 Surstylus with a distinct posteroapical emargination, anterior setae along apical half irregularly separated (Figs 25.2, 26.2)

- Surstylus with posteroapical corner gently tapered or with a slight depression, anterior setae along apical half relatively evenly separated (Fig. 24.2) (Dominican Republic)......

C. paraiso sp. $\mathrm{n}$.

12 Anterior edge of surstylus straight (Fig. 25.2); postgonite gently constricted at about apical quarter, angles created $\sim 50-60^{\circ}$, almost symmetrical (Fig. 25.3) (Mexico).

C. bolanosi sp. $\mathrm{n}$.

- Anterior edge of surstylus sinuate (Fig. 26.2); postgonite sharply constricted at about apical quarter, angles created $\sim 90^{\circ}$, strongly asymmetrical (Fig. 26.3) (Costa Rica) ............

C. dolabratus sp. $\mathrm{n}$.

13 Posterolateral lobes of S5 short and stout (Fig. 22.1); medial connecting sclerite elongate, rectangular; cercus with a single large medial seta and few smaller setulae; surstylus leaf-like with a sharp apical extension (Fig. 22.2); postgonite angled downwards in the apical third with a small, triangular preapical lobe (Fig. 22.3) (widespread across Central America) .....

.C. ganchopico sp. n.

- Posterolateral lobes of S5 long and thin (Fig. 17.1); medial connecting sclerite short, triangular; cercus with numerous 
smaller setae in addition to large medial seta; surstylus with a broad anterobasal lobe and a triangular preapical lobe, resembling a sock (Fig. 17.2); postgonite broadly emarginate apically (Fig. 17.3) (Ecuador)................... C. peckorum sp. n.

14 Anterior margin of S5 with two large lobes; posterior edge of S5 with a dense brush of setae along entire width (Figs 9.1, 10.1); posterolateral lobe of S5 curved inwards, often hidden by the setal brush..... .. 15

- Anterior margin of S5 unmodified or with very small lobes (Figs 7.1, 8.1, 11.1, 13.1, 20.1); posterior edge of S5 sparsely setose or with a small medial cluster of setae but never with a dense brush of setae along entire length (Fig. 12.1); posterolateral lobe of S5 not strongly curved inwards, not hidden by a setal brush 16

15 Anterior lobes of S5 apically flared, with sharp corners (Fig. 9.1); medial connecting sclerite broad, bell-shaped with long, dense setulae; anterior edge of postgonite evenly sinuate (Fig. 9.3); apex of distiphallus with reticulated pattern; epiphallus small (Ecuador, Peru) C. elephantus sp. $\mathrm{n}$.

- Anterior lobes of S5 with rounded corners, not apically flared (Fig. 10.1); medial connecting sclerite thin, V-shaped with apical pair of setae; anterior edge of postgonite straight or very unevenly sinuate (Fig. 10.3); apex of distiphallus finely grooved but without reticulated pattern; epiphallus extremely large and curved, resembling a hawk beak (Fig. 10.3) (Brazil, Costa Rica, Venezuela).... C. ventrisetis $\mathrm{sp} . \mathrm{n}$.

16 Main body of S5 long-setose (Figs 7.1, 8.1); posterolateral lobes of S5 well separated from lateral edges; surstylus with several ventral lobes (Figs 7.2, 8.2); epiphallus triangular and distinct 17

- Main body of S5 mostly bare; posterolateral lobes of S5 continuous with lateral edges; surstylus relatively simple without additional ventral lobes (Figs 11.2, 12.2, 13.3, 20.3); epiphallus rectangular or indistinct....

.. 18

17 Surstylus approximately C-shaped with two pointed ventral lobes separated by a triangular cleft (Fig. 8.2); posteromedial edge of S5 evenly rounded, without a tab (Fig. 8.1); postgonite slightly widened medially with apex a single point (Fig. 8.3) (Jamaica) C. jamaicensis sp. $\mathrm{n}$.
Surstylus short with two elongate, finger-like ventral lobes bearing several lateral setae (Fig. 7.1); posteromedial edge of S5 with a short rectangular tab (Fig. 7,1); postgonite distinctly broadened medially with apex split into two points (Fig. 7.3) (Costa Rica)................................ . metroidiformis sp. n.
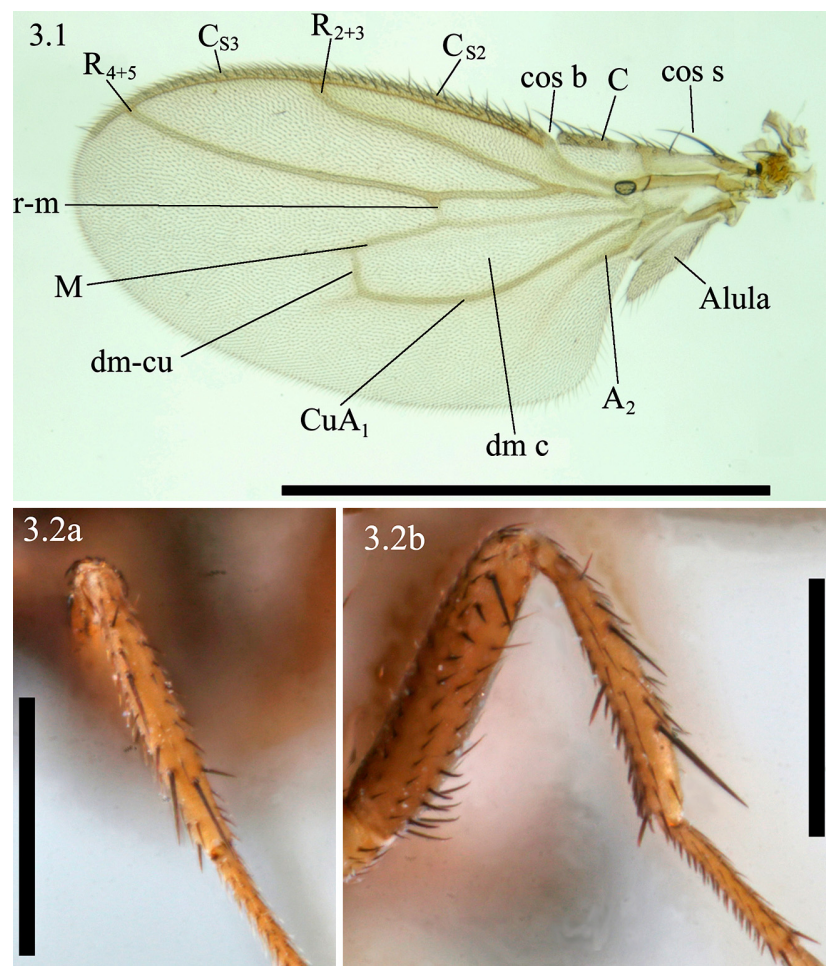

Figs 3.1-3.2. Appendage illustrations of male Chespiritos extendido sp. n. paratypes. 3.1 - left wing of Argentinian male; 3.2a - dorsal view of left mid tibia showing chaetotaxy of Ecuadorian male (debu00111716); $3.2 \mathrm{~b}$ - anterior view of left mid tibia showing chaetotaxy of Ecuadorian male (debu00111716). Abbreviations: C - costa, cos s - costagial seta, cos b - costal break, $\mathrm{C}_{\mathrm{s} 2}$ - costal sector $2, \mathrm{C}_{\mathrm{s}}-$ costal sector $3, \mathrm{dm} \mathrm{c}-\mathrm{dm}$ cell. Scale bars: $1.0 \mathrm{~mm}$ for 3.1 and $0.25 \mathrm{~mm}$ for 3.2 .
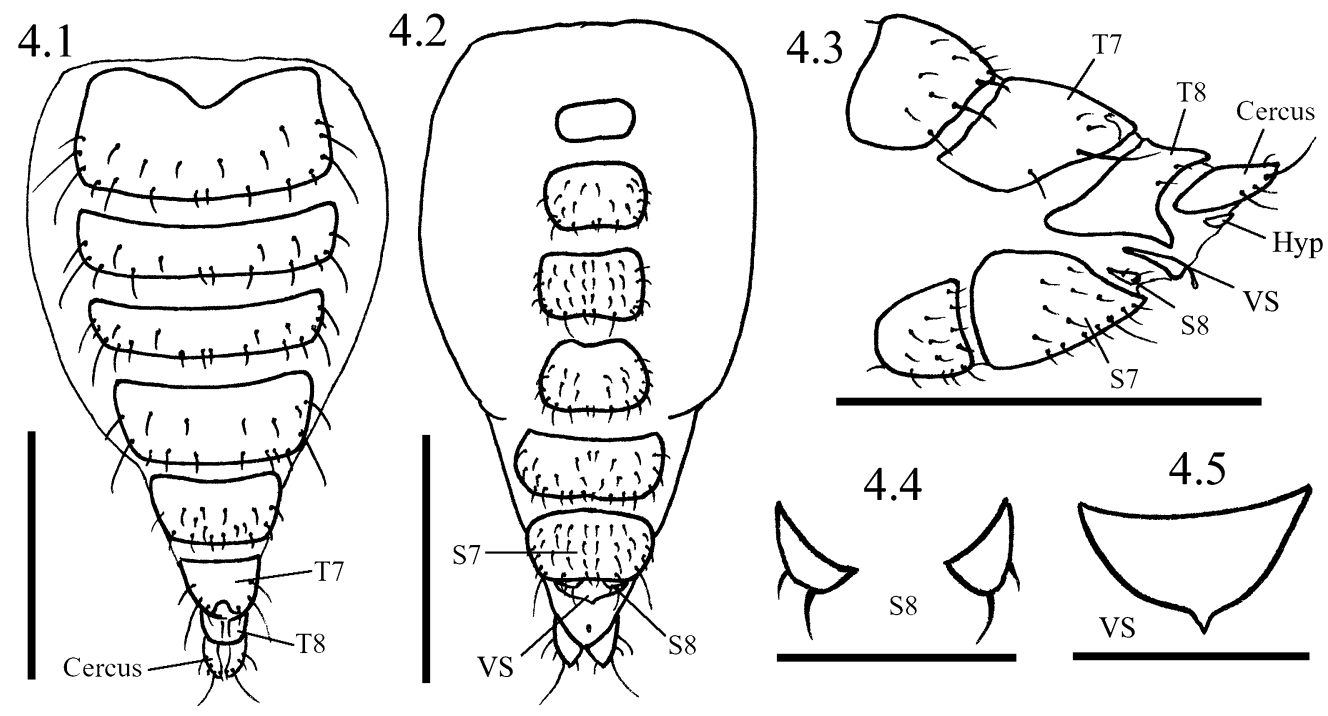

Figs 4.1-4.5. Female abdominal structures of Chespiritos jamaicensis sp. n. paratype. 4.1 - dorsal view of abdomen; $4.2-$ ventral view of abdomen; 4.3 - lateral view of female terminalia; 4.4 - sternite $8 ; 4.5$ - vaginal sclerite. Abbreviations: Hyp - hypoproct, $S 7$ - sternite 7 , S8 - sternite 8, T7 - tergite 7, T8 - tergite 8, VS - vaginal sclerite. Scale bars $0.50 \mathrm{~mm}(4.1-4.3), 0.125 \mathrm{~mm}(4.4$ and 4.5$)$. 

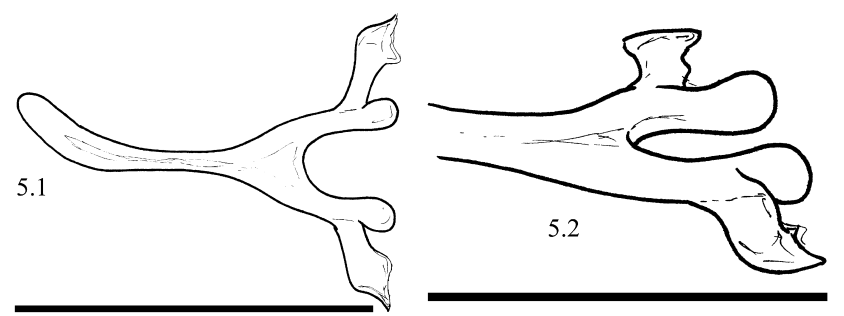

Figs 5.1-5.2. Hypandrium of male Ecuadorian Chespiritos extendido sp. n. paratype (debu00111716). 5.1 - hypandrium, dorsal; 5.2 - hypandrium, dorsolateral. Scale bars: $0.20 \mathrm{~mm}(5.1)$, $0.10 \mathrm{~mm}(5.2)$.

18 S5 with a pair of smaller, bare posteromedial lobes angled inwards (Fig. 20.1); surstylus very long (length greater than height of epandrium), leaf-shaped (Fig. 20.2); postgonite bent anteriorly in apical third at a distinct angle, causing ventral edge to be flattened, resembling a stocking (Fig. 20.3) (widespread across southern Central and northern South America)

C. coronatus sp. $\mathrm{n}$.

- S5 without posteromedial lobes; surstylus not as large, length less than height of epandrium; postgonite thin and tapered ...

.. 19

19 S5 with a broad posteromedial lobe bearing a pair of stout medial setae (Fig. 13.1); surstylus elongate with a triangular anteromedial lobe (Fig. 13.2); postgonite angled downwards in apical third with a rounded posteromedial lobe (Fig. 13.3) (Peru)... C. balrogiformis sp. $\mathrm{n}$.

- S5 with posteromedial surface unmodified; surstylus rectangular or triangular but without a triangular anteromedial lobe; postgonite slightly curved with a triangular lobe originating from the posterobasal third, not angled downwards in apical third (Figs 11.3, 12.3)

20

20 Posterolateral lobes of S5 bent inwards and extending medially to just below inner edges of anterior lobes (Fig. 11.1); S5 with sparse setae along posteromedial margin; surstylus short, rectangular with an apical lobe about as long as main portion angled posterolaterally (Fig. 11.2); distiphallus with a single broad apical lobe (Fig. 11.3) (Costa Rica)

C. chicobrazos sp. $\mathrm{n}$

- Posterolateral lobes of S5 bent inwards slightly but not extending medially (Fig. 12.1); S5 with a brush of setulae along posteromedial margin; surstylus elongate, triangular, angled posteriorly (Fig. 12.2); distiphallus with two elongate apical lobes, resembling a flower (Fig. 12.3) (Costa Rica)... C. gladiator $\mathrm{sp} . \mathrm{n}$.

\section{Species descriptions}

The following species descriptions are almost entirely restricted to the male and female terminalia. Other external characters were carefully examined and, with the exception of a few features included in the species descriptions, did not differ significantly between species. Species descriptions are arranged in the same order the species appear on the phylogenetic tree (Fig. 27).

\section{Chespiritos calceus sp. $\mathbf{n}$.}

(Figs 6.1-6.3)

ZooBank taxon LSID:

\section{D93D79A7-4345-4E94-86AF-AAE662CE0B53}

\section{Description}

Body length. Male $2.0 \mathrm{~mm}$.

General. Eye height $\sim 2.5 \times$ genal height. Mid femur with ventral row of 3 setae on proximal quarter. Distance between crossveins dm-cu and $\mathrm{r}-\mathrm{m} \sim 2.5 \times$ length of $\mathrm{dm}-\mathrm{cu}$.

Male abdomen. S5 with scattered setae, a pair of triangular, long-setose posterolateral lobes each terminating in thin, curved extensions; posterolateral lobes connected to main body of S5 via a membranous sheet posteriorly edged by a thin sclerite with a pair of reclinate setae; S5 medially short, length $\sim 0.20 \times$ width. Epandrium uniformly longsetose. Cercus pad-like. Surstylus short, long-setose, shoeshaped with a rectangular lobe extending posteriorly. Postgonite dark, flattened, curved forward along entire length, apex broadened and truncate. Basiphallus stout, rectangular; epiphallus small, rounded and directed ventrally. Distiphallus with basal third sclerotized and tubular, apical two-thirds membranous with a broad, scoop-like (when viewed dorsolaterally) dorsal lobe and a ventral lobe distinctly curved downwards, dorsoapical quarter reticulated.

Female unknown.

Type material. Holotype: PERU: Madre de Dios: Zona Reserva Manu, Pakitza, $11^{\circ} 57^{\prime} 00.0^{\prime \prime} \mathrm{S}, 71^{\circ} 17^{\prime} 0.00^{\prime \prime} \mathrm{W}, 400 \mathrm{~m}$, Malaise trap \#3, 18.-23.ii.1992, B. Brown \& D. Feener, (ô, LACM).

Type locality. Peru, Madre de Dios Department, Pakitza.

Etymology. This name refers to the resemblance between the surstylus and a small boot or shoe (Latin 'calceus': shoe, boot, buskin).

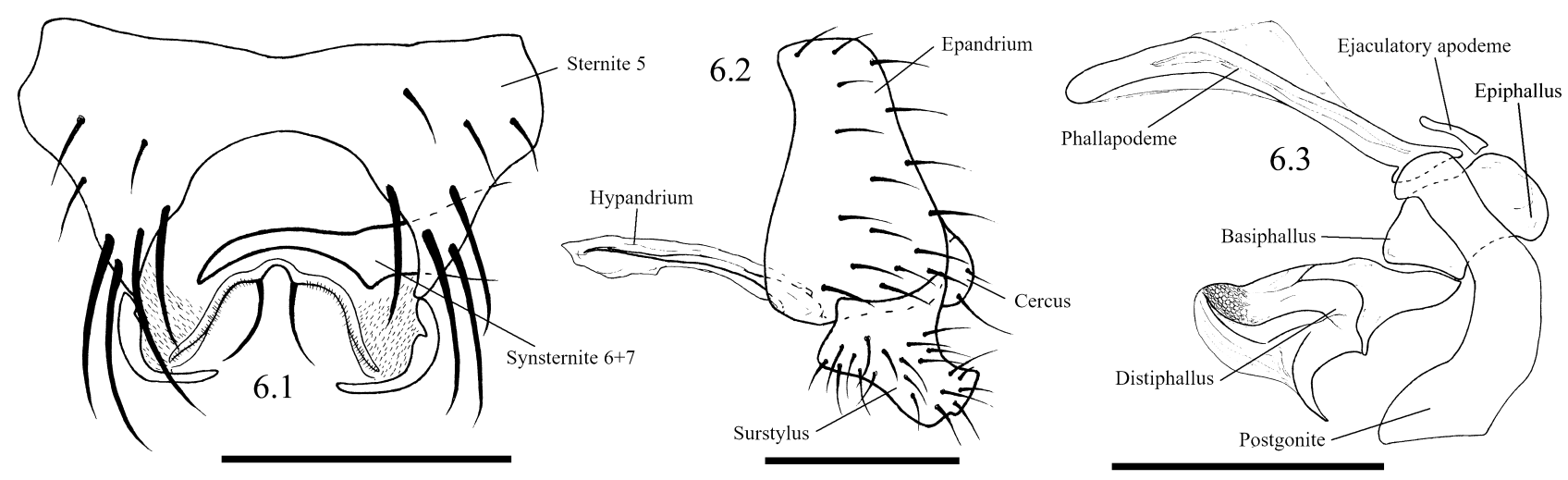

Figs 6.1-6.3. Chespiritos calceus sp. n., holotype male abdominal structures. 6.1 - S5, ventral; 6.2 - terminalia, lateral; 6.3 - aedeagus and associated structures, lateral. Scale bars: $0.20 \mathrm{~mm}$. 


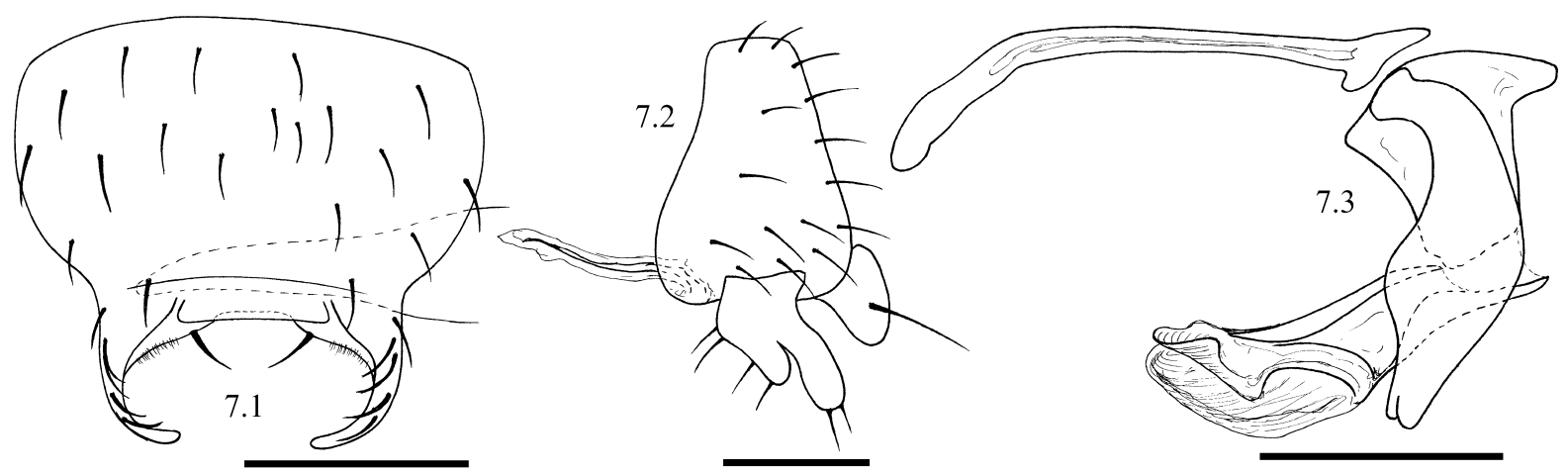

Figs 7.1-7.3. Chespiritos metroidiformis sp. n., holotype male abdominal structures. 7.1 - S5, ventral; 7.2 - terminalia, lateral; 7.3 - aedeagus and associated structures, lateral. Scale bars: $0.20 \mathrm{~mm}$.

Distribution. This species is known only from its type locality in Peru.

\section{Chespiritos metroidiformis sp. $\mathbf{n}$.}

(Figs 7.1-7.3)

ZooBank taxon LSID:

C5CEB3AA-2AE9-4F06-8D22-692211020EE0

\section{Description}

Body length. Males 1.6-1.7 mm.

General. Eye height $\sim 2.5 \times$ genal height. Mid femur with ventral row of 3 setae on proximal quarter. Distance between crossveins dm-cu and $\mathrm{r}-\mathrm{m} \sim 2.0 \times$ length of $\mathrm{dm}-\mathrm{cu}$.

Male abdomen. S5 uniformly setose with 1 pair of incurved posterolateral lobes, each with numerous stout setae; lobes connected by a membranous sheet with 2 me- dial setae; S5 medially long, length $\sim 1.0 \times$ width. Epandrium uniformly long-setose. Cercus pad-like with triangular ventral margin. Surstylus distally bilobed, anterior lobe shorter than posterior lobe, both with patches of setae. Postgonite dark, decurved, medially expanded and apically bifurcated. Basiphallus large, rectangular; epiphallus triangular, rounded apically and directed posteriorly. Distiphallus with basal half heavily sclerotized and tubular, apical half membranous with a large, scoop-like ventral lobe and a triangular dorsal lobe.

Female unknown.

Type material. Holotype: COSTA RICA: Heredia: Heredia, $10 \mathrm{~km}$ N San José, INBioparque (formerly Biodiversity Garden), 3.vi.1998, S.A. Marshall (ð̂, MNCR). Paratype: COSTA RICA: same data as holotype ( $1 \delta^{\lambda}$, DEBU).

Type locality. Costa Rica, Heredia Province, INBioparque.

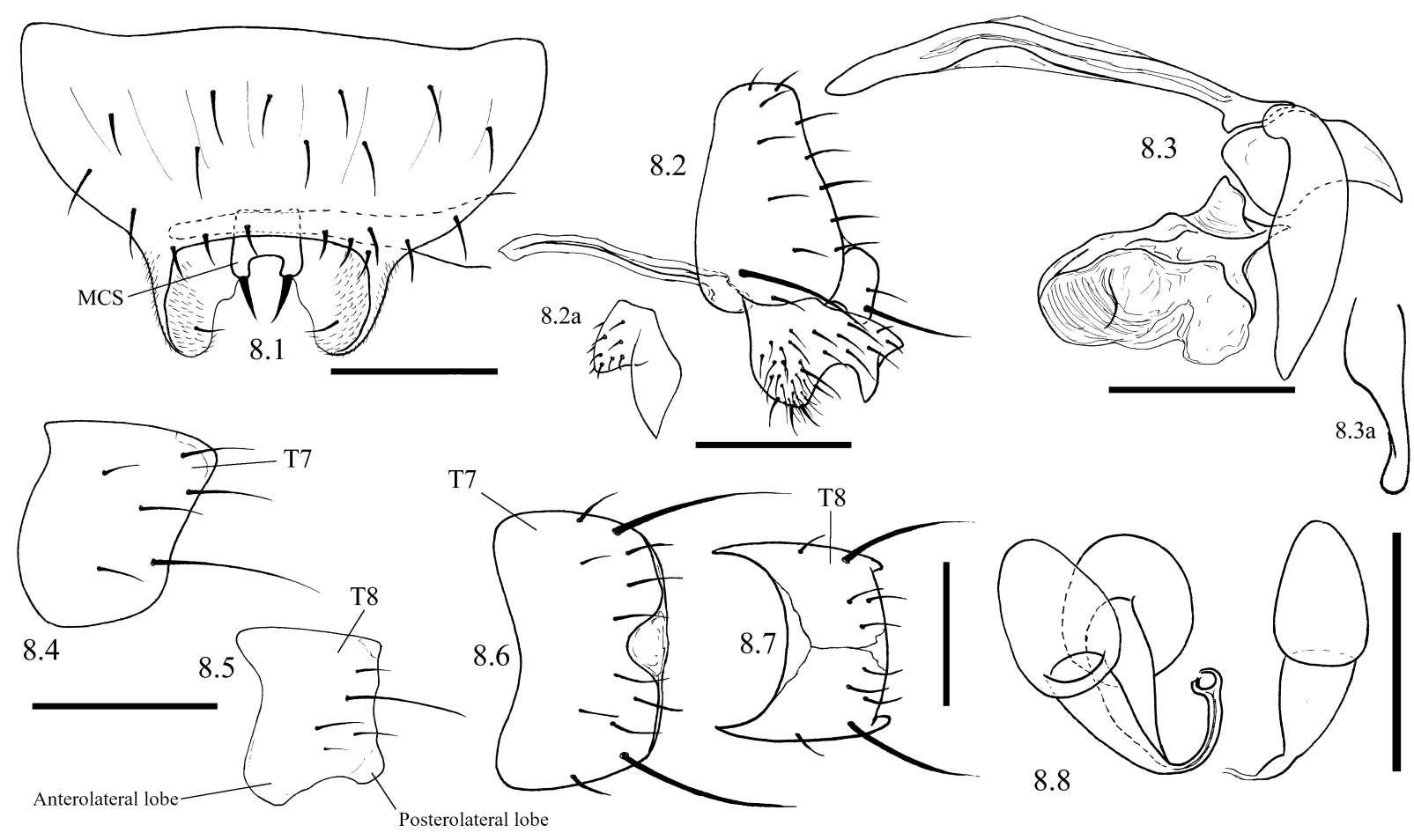

Figs 8.1-8.8. Chespiritos jamaicensis sp. n., male (holotype) and female abdominal structures. 8.1 - male S5, ventral; 8.2 - terminalia, lateral; $8.2 \mathrm{a}$ - surstylus, posterior; 8.3 - aedeagus and associated structures, lateral; $8.3 \mathrm{a}$ - postgonite, posterior; 8.4 - female T7, lateral; 8.5 - female T8, lateral; 8.6 - female T7, dorsal; 8.7 - female T8, dorsal; 8.8 - spermathecae. Abbreviations: MCS - medial connecting sclerite. Scale bars: $0.20 \mathrm{~mm}$ except spermathecae $(0.10 \mathrm{~mm})$. 

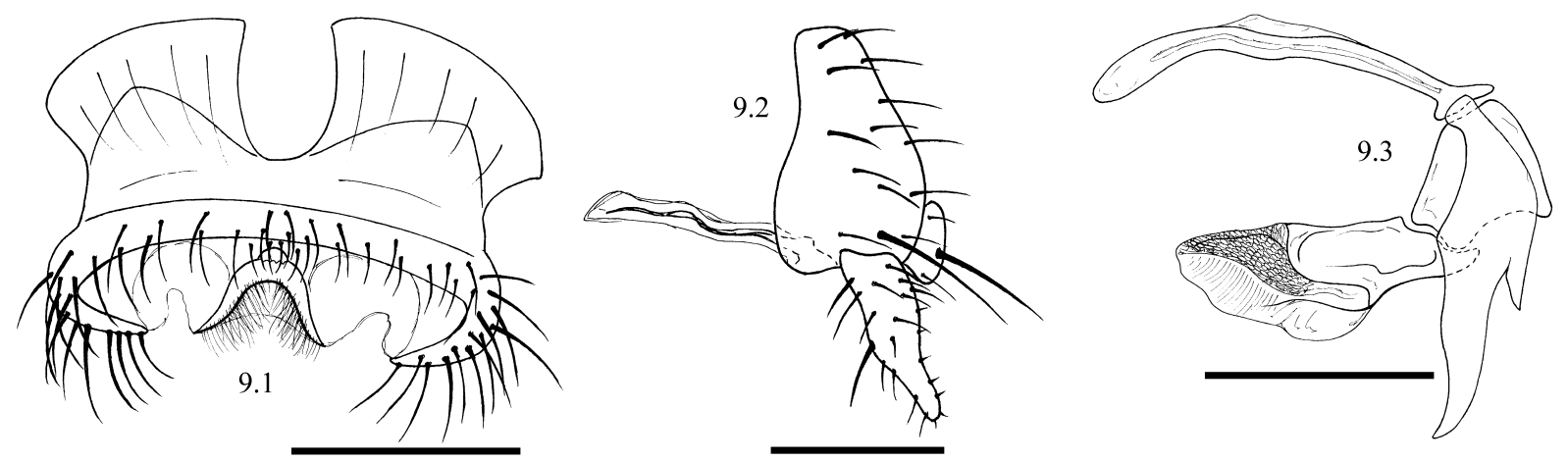

Figs 9.1-9.3. Chespiritos elephantus sp. n., holotype male abdominal structures. 9.1 - S5, ventral; 9.2 - terminalia, lateral; 9.3 - aedeagus and associated structures, lateral. Scale bars: $0.20 \mathrm{~mm}$.

Etymology. This name reflects the similarities between the fifth sternite of Chespiritos metroidiformis and the bulbous body and large mandibles of the alien species "Metroid" from Nintendo's video game series of the same name.

Distribution. This species is known only from its type locality in Costa Rica.

\section{Chespiritos jamaicensis sp. $\mathbf{n}$.}

(Figs 4.1-4.5, 8.1-8.8)

ZooBank taxon LSID:

0BF13D2F-FD85-4147-8693-E24E74C99D23

\section{Description}

Body length. Male $1.9 \mathrm{~mm}$, females $2.0 \mathrm{~mm}$.

General. Eye height $\sim 2.0 \times$ genal height. Mid femur with ventral row of 4 setae on proximal quarter. Distance between crossveins dm-cu and $\mathrm{r}-\mathrm{m} \sim 2.5 \times$ length of $\mathrm{dm}-\mathrm{cu}$.

Male abdomen. S5 large, broad, with a pair of short, bare posteromedial lobes that curl upwards slightly; S5 medially long, length $\sim 0.50 \times$ width. Medial connecting sclerite stout, posteriorly emarginated with a pair of stout setae. Epandrium uniformly long-setose with a large ventrolateral seta. Cercus pad-like. Surstylus complex, with two distinct ventral lobes: long-setose basal lobe extending to a rounded point and bare apicoventral lobe extending to a sharp point. Postgonite dark, tapered and decurved, anterior edge slightly sinuate, basal half with a broad lateral lobe, apex with rounded lateral lobe. Basiphallus stout, rectangular; epiphallus large, curved and directed posteroventrally. Distiphallus with basal third heavily sclerotized and tubular with sclerotization extending dorsally to apex, apical two-thirds highly membranous with a large, bilobed, scoop-like lobe.

Female abdomen. T7 with 5 pairs of smaller setae and 1 pair of larger posterolateral setae; width $\sim 1.50 \times$ width of T3; posteromedial notch semicircular, extending anteriorly $\sim 0.25 \times$ length of $\mathrm{T} 7$, posterior width $\sim 0.25 \times$ width of T7; lacks anterolateral lobe. T8 with 4 pairs of smaller setae and 1 pair of large posterolateral setae; T8 with small, desclerotized posteromedial triangle; both antero- and posterolateral lobes are small and directly connected to T8. Apical bulb of spermathecae elongate, egg-shaped and smooth, equal in length to smooth, elongate basal bulb.
Type material. Holotype: JAMAICA: St. Ann Parish, Ocho Rios, Fern Gully, 19.ii.-1.iii.1989, flight intercept trap, D.H. Lindeman $(\hat{0}, \mathrm{CNCI})$. Paratypes: JAMAICA: same data as holotype (1, CNCI); St. Andrew Parish, Hardwar Gap, 1220 m, 6.vii.1966, Howden \& Becker (1 9, CNCI).

Type locality. Jamaica, Ocho Rios, Fern Gully.

Etymology. This name reflects the restriction of this species to Jamaica, where it is the only species of Chespiritos.

Distribution. This species is only known from Jamaica.

\section{Chespiritos elephantus sp. $\mathbf{n}$.}

(Figs 9.1-9.3)

ZooBank taxon LSID:

04D34191-1EEE-4FA1-990B-6B6E5CDFAF3B

\section{Description}

Body length. Males 2.0-2.4 mm.

General. Eye height $\sim 2.5 \times$ genal height. Mid femur with ventral row of 4 setae on proximal quarter. Distance between crossveins dm-cu and r-m $\sim 2.5 \times$ length of dm-cu.

Male abdomen. S5 broad with 2 small incurved longsetose posterolateral lobes; posterior edge with a dense brush-like band of setae; S5 medially short, length $\sim 0.25 \times$ width with 2 large rectangular anterior lobes. Medial connecting sclerite bell-shaped, densely long-setulose along posterior edge, posteriorly emarginate. Epandrium uniformly long-setose with a large ventrolateral setae. Cercus pad-like. Surstylus elongate, long-setose and tapered with apical half slightly angled posteriorly. Postgonite dark, blade-like with anterior margin slightly sinuate and a small, distally projecting lobe originating from posterior edge of the basal third. Basiphallus large, rectangular; epiphallus small, triangular, apically rounded and directed posteriorly. Distiphallus with basal half heavily sclerotized and tubular, apical half membranous with a broad, scooplike, apicodorsally reticulated lobe.

Female unknown.

Type material. Holotype: ECUADOR: Pichincha: Maquipucuna Biological Reserve, 0 ${ }^{\circ} 7^{\prime} 26.8^{\prime \prime} \mathrm{N}, 78^{\circ} 37^{\prime} 46.8^{\prime \prime} \mathrm{W}, 1200 \mathrm{~m}$, compost pan traps, 27.-29.x.1999, S.A. Marshall, debu00111725 (ð, QCAZ). Paratypes: ECUADOR: Napo: Yasuni National Park, Yasuni Research Station, rainforest Malaise trap, 3.-20. xi.1998, Pape \& Viklund (1ठ̂, DEBU); same data as holotype (1 $\left.\partial^{\top}, Q C A Z\right)$. PERU: Cusco: Cock-of-the-Rock Lodge, NE Paucartambo, $13^{\circ} 3^{\prime} 18^{\prime \prime} \mathrm{S}, 71^{\circ} 32^{\prime} 42^{\prime \prime} \mathrm{W}, 1120 \mathrm{~m}$, flight intercept trap, 


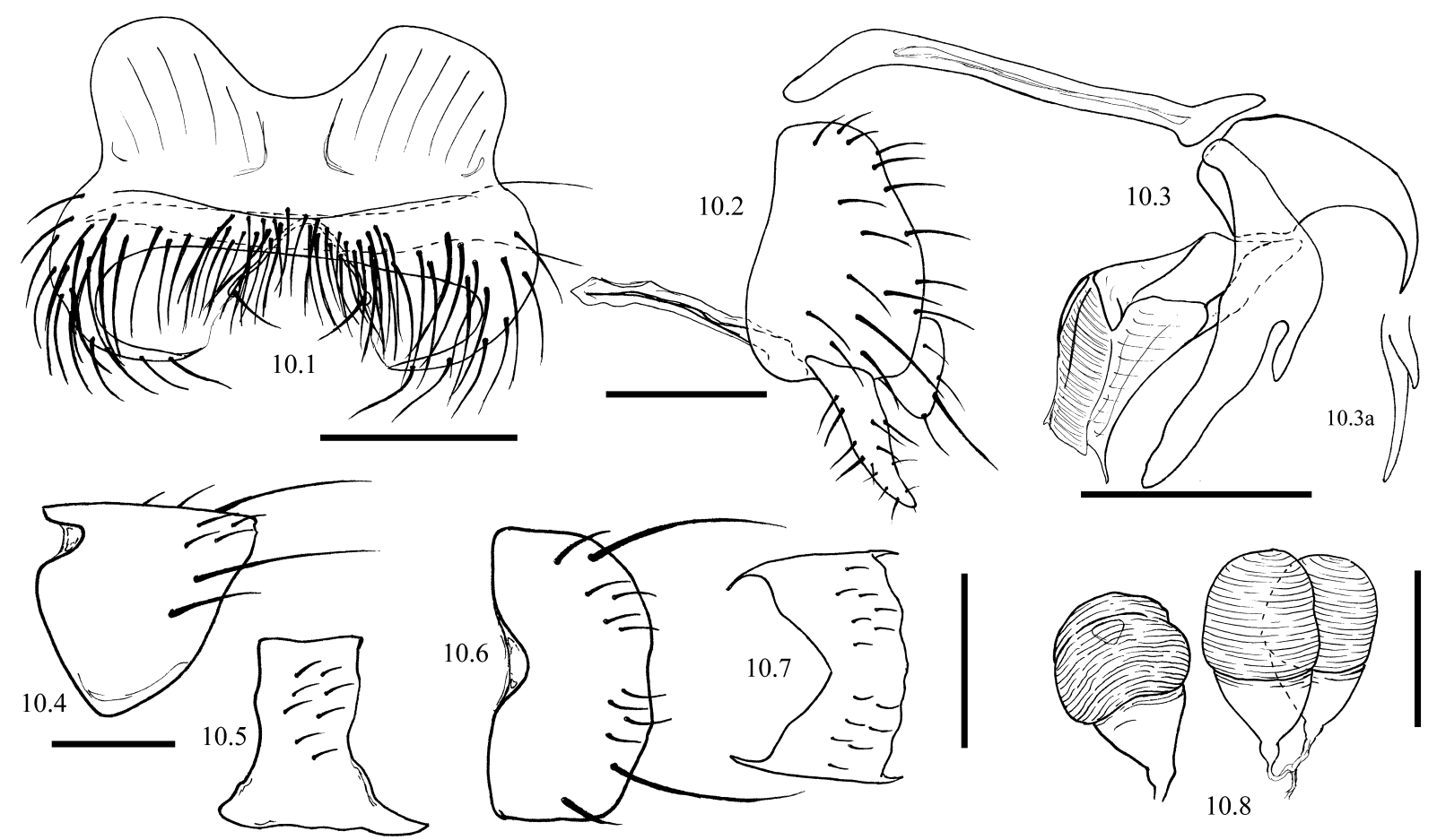

Figs 10.1-10.8. Chespiritos ventrisetis sp. n., male (holotype) and female abdominal structures. 10.1 - male S5, ventral; 10.2 - terminalia, lateral; 10.3 - aedeagus and associated structures, lateral; $10.3 \mathrm{a}$ - postgonite, posterior; 10.4 - female T7, lateral; 10.5 - female T8, lateral; 10.6 - female T7, dorsal; 10.7 - female T8, dorsal; 10.8 - spermathecae. Scale bars: $0.20 \mathrm{~mm}$ except spermathecae $(0.10 \mathrm{~mm})$.

4.-9.xi.2007, D. Brzoska (2ð, MUSM); Madre de Dios: Pantiacolla Lodge, Alto Madre de Dios River, $12^{\circ} 39^{\prime} 18^{\prime \prime} \mathrm{S}, 71^{\circ} 13^{\prime} 54^{\prime \prime} \mathrm{W}$, $420 \mathrm{~m}$, flight intercept trap, 14.-19.xi.2007, D. Brzoska $(1 \overbrace{}^{\top}$, DEBU).

Type locality. Ecuador, Pichincha Province, Maquipucuna Biological Reserve.

Etymology. This name refers to the large anterior lobes of the male fifth sternite, the elongate postgonites and the phallus, which together resemble the ears, tusks and trunk of an elephant (Latin 'elephantus': elephant).

Distribution. This species is known from Ecuador and Peru.

\section{Chespiritos ventrisetis sp. $\mathbf{n}$.}

(Figs 10.1-10.8)

ZooBank taxon LSID:

E18968F5-1137-4EC1-B630-345027C417ED

\section{Description}

Body length. Males $1.8-2.0 \mathrm{~mm}$, females $1.7-2.4 \mathrm{~mm}$.

General. Eye height $\sim 2.5 \times$ genal height. Mid femur with ventral row of 4 setae on proximal quarter. Distance between crossveins dm-cu and $\mathrm{r}-\mathrm{m} \sim 2.5 \times$ length of $\mathrm{dm}-\mathrm{cu}$.

Male abdomen. S5 broad with 2 small incurved longsetose posterolateral lobes; posterior edge with a dense brush-like band of setae; S5 medially short, length $\sim 0.20 \times$ width with a single large, anteromedially emarginate anterior lobe. Medial connecting sclerite thin, inverted V-shaped and bearing a pair of setae; hidden under posterior edge of S5. Epandrium uniformly long-setose with 1-2 large ventrolateral setae. Cercus pad-like. Surstylus elongate, long-setose and tapered with apical third slightly angled posteriorly. Postgonite dark, slightly decurved, blade-like with anterior margin slightly sinuate and a small, distally projecting lobe originating from the posterior edge of the basal third. Hypandrium unique: anterior lobe long, posterior fork of arms distinctly long, about as long as anterior fork of arms. Basiphallus stout, square; epiphallus extremely large, curved and directed posteriorly. Distiphallus with basal half heavily sclerotized and tubular, apical half membranous, somewhat tubular and angled downwards with a slightly bifurcated apex.

Female abdomen. T7 with 4 pairs of smaller setae and 2 pairs of larger posterolateral setae; width $\sim 1.50 \times$ width of T3; lacks posteromedial notch but has rounded anteromedial notch, extending posteriorly $\sim 0.17 \times$ length of $\mathrm{T} 7$, anterior width $\sim 0.33 \times$ width of $\mathrm{T} 7$; anterolateral lobe absent. T8 with 7 pairs of smaller setae; both antero- and posterolateral lobes triangular and connected from T8, posterolateral lobe elongate. Apical bulb of spermathecae stout, spherical, grooved with apical invagination, $\sim$ equal to length of smooth, stout basal bulb.

Type material. Holotype: COSTA RICA: Puntarenas: Monteverde Biological Reserve, Monteverde Biological Station, $1500 \mathrm{~m}$, white pans in kitchen compost, 13.vi.2000, M. Buck, debu00131197 ( $\lesssim$, MNCR). Paratypes: BRAZIL: Santa Catarina: Nova Teutonia, ix.1949, F. Plaumann (1ð̂, USNM); Nova

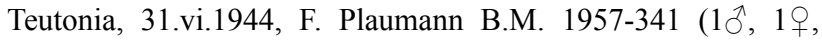
BMNH); Nova Teutonia, 7.viii.1944, F. Plaumann B.M. 1957341 (1 9 , BMNH); Nova Teutonia, 22.ix.1949, F. Plaumann B.M. 1957-341 (1 9, BMNH); Nova Teutonia, 10.x.1949, F. Plaumann B.M. 1957-341 (2犬, 5, BMNH); Nova Teutonia, 6.iii.1950, F. Plaumann B.M. 1957-341 (10ิ, BMNH); Nova Teutonia, $27^{\circ} 11^{\prime} 0.00^{\prime \prime} \mathrm{S}, 52^{\circ} 23^{\prime} 0.00^{\prime \prime} \mathrm{W}, 300-500 \mathrm{~m}$, vii. 1958 , F. Plaumann $(2 \circ, \mathrm{CNCI})$; Nova Teutonia, $27^{\circ} 11^{\prime} 0.00^{\prime \prime} \mathrm{S}, 52^{\circ} 23^{\prime} 0.00^{\prime \prime} \mathrm{W}$, 300-500 m, ix.1960, F. Plaumann ( $3 \overbrace{}^{\Uparrow}, 3$ ㅇ, CNCI); Nova Teu- 


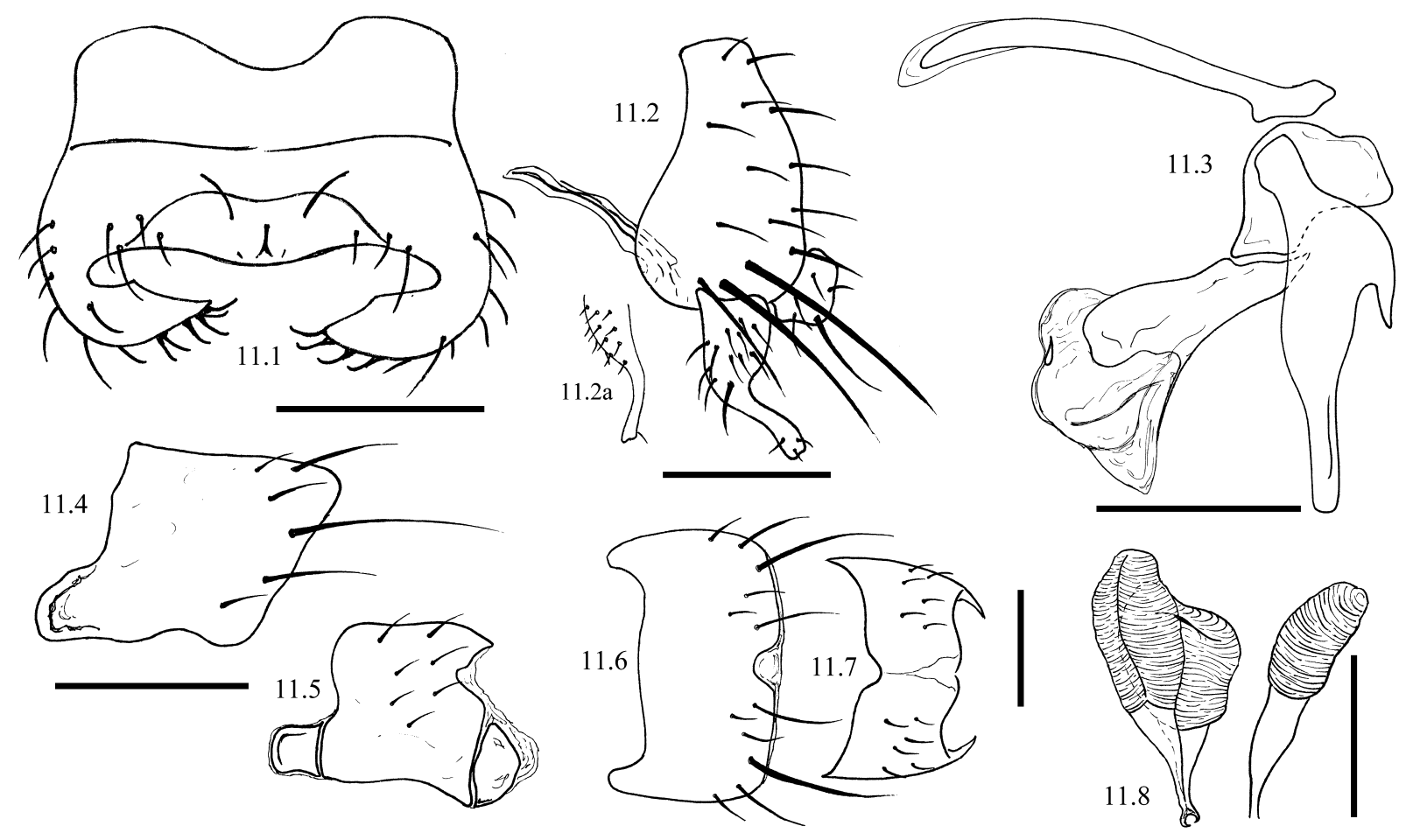

Figs 11.1-11.8. Chespiritos chicobrazos sp. n., male (holotype) and female abdominal structures. 11.1 - male S5, ventral; 11.2 - terminalia, lateral; $11.2 \mathrm{a}$ - surstylus, posterior; 11.3 - aedeagus and associated structures, lateral; 11.4, - female T7, lateral; 11.5 - female T8, lateral; 11.6 - female T7, dorsal; 11.7 - female T8, dorsal; 11.8 - spermathecae. Scale bars: $0.20 \mathrm{~mm}$ except spermathecae $(0.10 \mathrm{~mm})$.

tonia, $27^{\circ} 11^{\prime} 0.00^{\prime \prime} \mathrm{S}, 52^{\circ} 23^{\prime} 0.00^{\prime \prime} \mathrm{W}, 300-500 \mathrm{~m}$, vi.-viii. 1961 , F. Plaumann $(1 \hat{\jmath}, 4+\mathrm{CNCI})$; Nova Teutonia, $27^{\circ} 11^{\prime} 0.00^{\prime \prime} \mathrm{S}$, $52^{\circ} 23^{\prime} 0.00^{\prime \prime} \mathrm{W}, 300-500 \mathrm{~m}$, ix.-xi.1962, F. Plaumann (7ठ̂, 13ㅇ, CNCI); Nova Teutonia, $27^{\circ} 11^{\prime} 0.00^{\prime \prime} \mathrm{S}, 52^{\circ} 23^{\prime} 0.00^{\prime \prime} \mathrm{W}, 300-500$ m, vi.-vii.1964, F. Plaumann $(5 \hat{\jmath}, 5$ ㅇ, CNCI $)$; Nova Teutonia, $27^{\circ} 11^{\prime} 0.00^{\prime \prime} \mathrm{S}, 52^{\circ} 23^{\prime} 0.00^{\prime \prime} \mathrm{W}, 300-500 \mathrm{~m}$, viii.-ix. 1965 , F. Plaumann $\left(2{ }^{\wedge}, 3+\right.$, $\left.\mathrm{CNCI}\right)$; Nova Teutonia, $27^{\circ} 11^{\prime} 0.00^{\prime \prime} \mathrm{S}$, $52^{\circ} 23^{\prime} 0.00^{\prime \prime} \mathrm{W}, 300-500 \mathrm{~m}$, ix.1972, F. Plaumann (1ठ, 1 , FMNH). COSTA RICA: Limón: Estrella Valley, Pandora, carrion trap, 20.ii.1984, H. Howden (1今̂, DEBU); same data as holotype (1q, MNCR). VENEZUELA: Monagas: Caripe, Guacharo caves, oilbird refuse piles, 20.iv.1986, S.A. Marshall $(9 \hat{\jmath}, 9+$, MIZA, DEBU).

Type locality. Costa Rica, Puntarenas Province, Monteverde Biological Reserve.

Etymology. This name refers to the dense brush of setae along the posterior edge of sternite 5 (Latin 'venter': belly, stomach).

Distribution. This species is widespread but has an apparently disjunct distribution, with no specimens having been collected between the southern end of Brazil and Venezuela.

\section{Chespiritos chicobrazos sp. $\mathbf{n}$.}

(Figs 11.1-11.8)

ZooBank taxon LSID:

A0E80937-D075-4D42-A381-A6753A1A3895

\section{Description}

Body length. Male $1.9 \mathrm{~mm}$, females $2.2-2.3 \mathrm{~mm}$.

General. Eye height $\sim 2.5 \times$ genal height. Mid femur with ventral row of 3 setae on proximal quarter. Distance between crossveins dm-cu and $\mathrm{r}-\mathrm{m} \sim 2.0-2.5 \times$ length of dm-cu.
Male abdomen. S5 with a pair of broad, long-setose posterolateral lobes projecting downwards and angled inwards; S5 medially short, length $\sim 0.25 \times$ width with a single large, anteromedially emarginate anterior lobe. Epandrium uniformly long-setose with a ventrolateral patch of large setae. Cercus pad-like. Surstylus rectangular, long-setose with a long, thin apical projection angled posterolaterally. Postgonite dark, narrowed in apical third with a small, distally-projecting lobe originating from the posterior edge of the basal third. Basiphallus large, ventromedially emarginate resembling a kidney bean; epiphallus small, rounded and directed posteriorly. Distiphallus with basal two-thirds heavily sclerotized and tubular, apical third highly membranous with a large, laterally folded, scoop-like lobe.

Female abdomen. T7 with 5 pairs of smaller setae and 1 pair of larger posterolateral setae; width $\sim 1.0 \times$ width of T3; posteromedial notch semicircular, extending anteriorly $\sim 0.25 \times$ length of $\mathrm{T} 7$, posterior width $\sim 0.16 \times$ width of $\mathrm{T} 7$; anterolateral lobe large and broadly triangular. T8 with 7 pairs of smaller setae and large, desclerotized posteromedial triangle; anterolateral lobe square and separated from $\mathrm{T} 8$, posterolateral lobe semicircular and separated from T8. Apical bulb of spermathecae elongate, slightly decurved and grooved, slightly longer than smooth, elongate basal bulb.

Type material. Holotype: COSTA RICA: Puntarenas: Monteverde Biological Reserve, 1500 m, 15.-20.viii.1986, L. Masner ( $\lesssim$, MNCR). Paratypes: COSTA RICA: same data as holotype (2q, MNCR, DEBU).

Type locality. Costa Rica, Puntarenas Province, Monteverde Biological Reserve. 


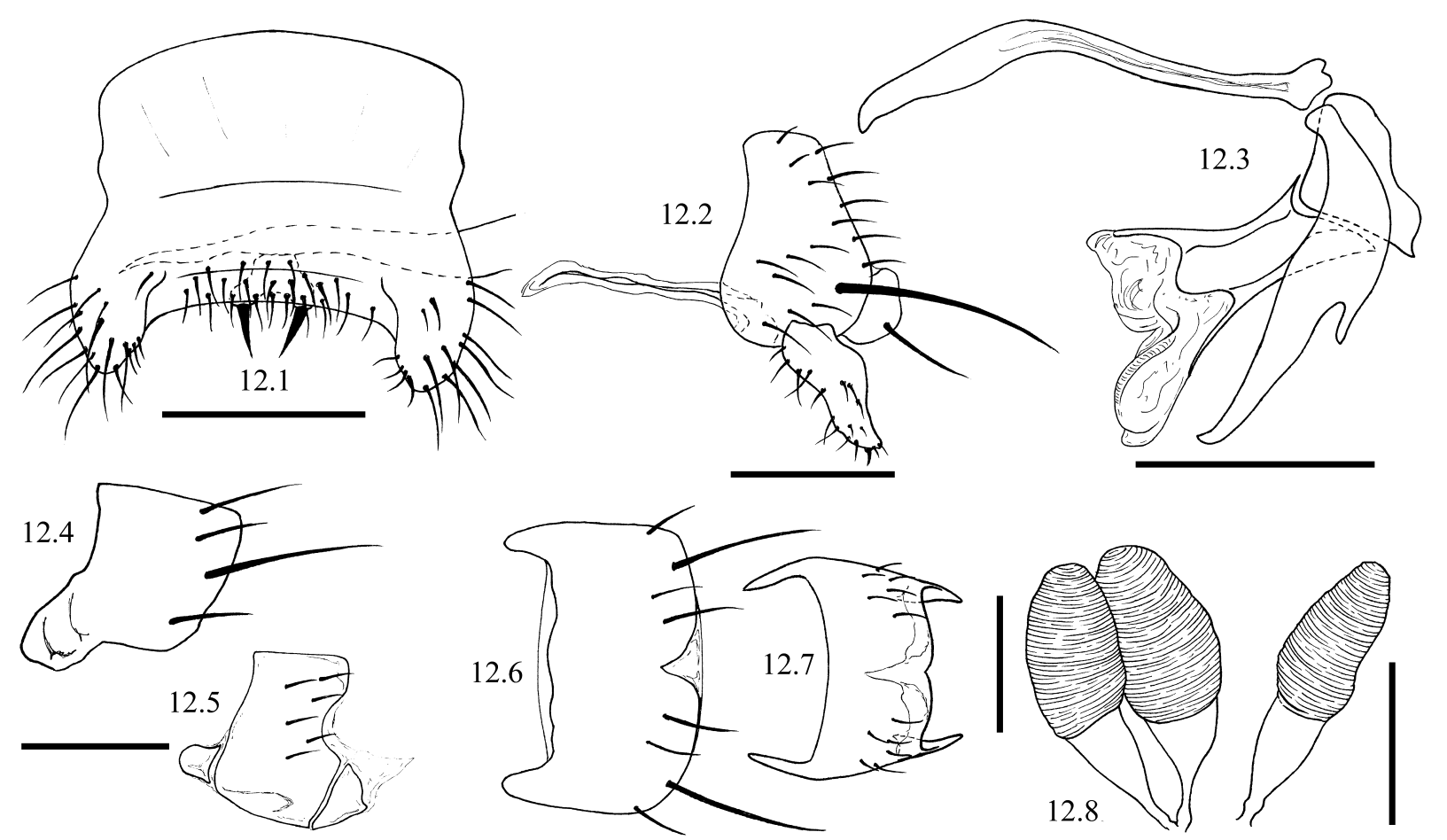

Figs 12.1-12.8. Chespiritos gladiator sp. n., male (holotype) and female abdominal structures. 12.1 - male S5, ventral; 12.2 - terminalia, lateral; 12.3 - aedeagus and associated structures, lateral; 12.4 - female T7, lateral; 12.5 - female T8, lateral; 12.6 - female T7, dorsal; 12.7 - female T8, dorsal; 12.8 - spermathecae. Scale bars: $0.20 \mathrm{~mm}$ except spermathecae $(0.10 \mathrm{~mm})$.

Etymology. This name refers to the posterolateral lobes of the fifth sternite, which resemble a pair of small arms (Spanish 'chico': small, little; Spanish 'brazo': arm, front limb).

Distribution. This species is known only from its type locality in Costa Rica.

\section{Chespiritos gladiator sp. $\mathrm{n}$.}

(Figs 12.1-12.8)

ZooBank taxon LSID:

695CFD19-B519-49DE-B73A-3453E500BE1F

\section{Description}

Body length. Males $1.9 \mathrm{~mm}$, females 1.9-2.0 mm.

General. Eye height $\sim 2.5 \times$ genal height. Mid femur with ventral row of 3 setae on proximal quarter. Distance between crossveins dm-cu and $\mathrm{r}-\mathrm{m} \sim 2.5 \times$ length of $\mathrm{dm}-\mathrm{cu}$.

Male abdomen. S5 with a pair of stout, incurved longsetose posterolateral lobes projecting downwards; S5 medially short, length $\sim 0.33 \times$ width with a single large, anterior lobe; posteromedial edge of S5 with a dense patch of setae. Medial connecting sclerite stout, posteriorly emarginated and bearing a pair of stout setae; hidden under posterior edge of S5. Epandrium uniformly longsetose with a large ventrolateral seta. Cercus with a slight ventromedial indentation. Surstylus elongate, long-setose and tapered with apex angled inwards; anterior edge with a row of long setae; apical half with a sparse patch of setae. Postgonite dark, slightly decurved, and blade-like with a small, distally projecting lobe originating from the posterior edge of the basal third. Hypandrium unique: anterior lobe with spatulate apex; anterior fork of arms broad and recurved apically, posterior fork of arms distinctly long, about half as long as anterior arms. Basiphallus stout, triangular; epiphallus small, triangular and directed posteriorly. Distiphallus with basal two-thirds heavily sclerotized and tubular, apical third membranous with a pair of smaller dorsolateral lobes and a large ventral lobe.

Female abdomen. T7 with 3 pairs of smaller setae and 1 pair of larger posterolateral setae; width $\sim 1.0 \times$ width of T3; posteromedial notch triangular, extending anteriorly $\sim 0.25 \times$ length of $\mathrm{T} 7$, posterior width $\sim 0.20 \times$ width of T7; anterolateral lobe large and rounded, angled downwards. T8 with 6 pairs of smaller setae and large, desclerotized posteromedial triangle; anterolateral lobe anteriorly rounded and separated from T8, posterolateral lobe triangular and separated from T8. Apical bulb of spermathecae elongate, conical and grooved, slightly longer than smooth, elongate basal bulb.

Type material. Holotype: COSTA RICA: San José: San Gerardo de Dota, 9³3'01.9"N, 8348'26.9"W, 2300 m, Savegre Lodge windows, 9.-10.viii.1995, D.C. Caloren (ठึ, MNCR). Paratypes: COSTA RICA: Puntarenas Monteverde Biological Reserve, 1500 m, 15.-20.viii.1986, L. Masner (2ᄋ, DEBU); same data as holotype (1ㅇ, MNCR); San José: San Gerardo de Dota, 9³3'01.9”N,

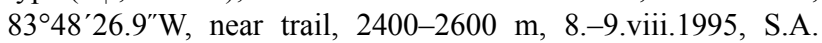
Marshall (1, MNCR).

Type locality. Costa Rica, San José Province, San Gerardo de Dota.

Etymology. This name refers to the fifth sternites, which look like the galea-style helmet worn by Roman gladiators (Latin 'gladiator': swordsman). The posterolateral lobes resemble the plates of the helmet that cover the sides of the face.

Distribution. This species is known only from Costa Rica. 

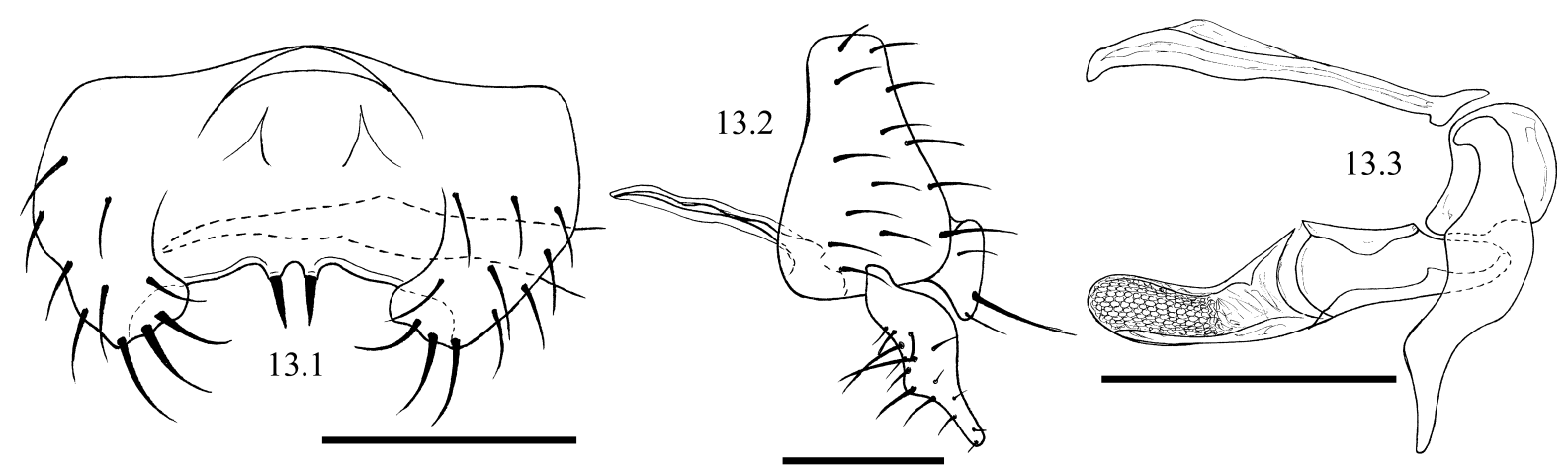

Figs 13.1-13.13. Chespiritos balrogiformis sp. n. - holotype male abdominal structures. 13.1 - S5, ventral; 13.2 - terminalia, lateral; 13.3 - aedeagus and associated structures, lateral. Scale bars: $0.20 \mathrm{~mm}$.

\section{Chespiritos balrogiformis sp. $\mathrm{n}$.}

(Figs 13.1-13.3)

ZooBank taxon LSID:

19DEEFE8-9062-4410-B580-D067DE8CAECA

\section{Description}

Length. Male $1.6 \mathrm{~mm}$.

General. Eye height $\sim 2.5 \times$ genal height. Mid femur with ventral row of 4 setae on proximal quarter. Distance between crossveins dm-cu and $\mathrm{r}-\mathrm{m} \sim 3.0 \times$ length of $\mathrm{dm}-\mathrm{cu}$.

Male abdomen. S5 complex, with a pair of large, rectangular, long-setose posterolateral lobes angled inwards and bare posteromedial lobe wrapping under posterolateral lobes; posteromedially with 2 stout setae; S5 medially short, length $\sim 0.20 \times$ width. Epandrium uniformly long-setose. Cercus pad-like. Surstylus elongate, triangular with a small triangular anteromedial lobe; anterior surface with numerous long setae, laterally with some small setae. Postgonite tapered, with anterior margin sinuate and apical third angled posteriorly. Basiphallus rectangular; epiphallus small, rounded and directed ventrally. Distiphallus with basal half heavily sclerotized and tubular, apical half semimembranous with 2 elongated dorsal and ventral sclerites supporting 3 scoop-like, apicolaterally reticulated lobes which form a tube.

Female unknown.

Type material. Holotype: PERU: Madre de Dios: Alto Madre de Dios River, Pantiacolla Lodge, 12 $2^{\circ} 9^{\prime} 18^{\prime \prime} \mathrm{S}, 7^{\circ} 13^{\prime} 54^{\prime \prime} \mathrm{W}$,
$420 \mathrm{~m}$, flight intercept trap, 14.-19.xi.2007, D. Brzoska, debu00356588 (ô, MUSM).

Type locality. Peru, Madre de Dios Department, Alto Madre de Dios River.

Etymology. This name refers to the fifth sternite, which resembles the head of the Balrog from J.R.R. Tolkien's The Lord of The Rings series, specifically the one represented in Peter Jackson's movie "Lord of the Rings: The Fellowship of the Ring".

Distribution. This species is known only from its type locality in Peru.

\section{Chespiritos anguineus sp. $\mathbf{n}$.}

(Figs 14.1-14.3)

ZooBank taxon LSID:

1194CF11-91EB-4033-A23A-953CE4E222EB

\section{Description}

Length. Male $2.0 \mathrm{~mm}$.

General. Eye height $\sim 2.5 \times$ genal height. Mid femur with ventral row of 4 setae on proximal quarter. Distance between crossveins dm-cu and r-m $\sim 2.5 \times$ length of $\mathrm{dm}-\mathrm{cu}$.

Male abdomen. S5 with 2 large, long-setose posterolateral lobes, each tipped with a distinctly larger, flattened seta; S5 medially short, length $\sim 0.10 \times$ width. Medial connecting sclerite very broad, triangular and bearing a pair of stout setae. Epandrium uniformly long-setose with 2 large ventrolateral setae. Cercus with large, ovular, long-setose ventral lobe. Surstylus elongate, thin, anteriorly long-setose with apical third bent posteriorly $90^{\circ}$ and tipped with stout seta. Postgonite dark, slightly sinuate along anterior

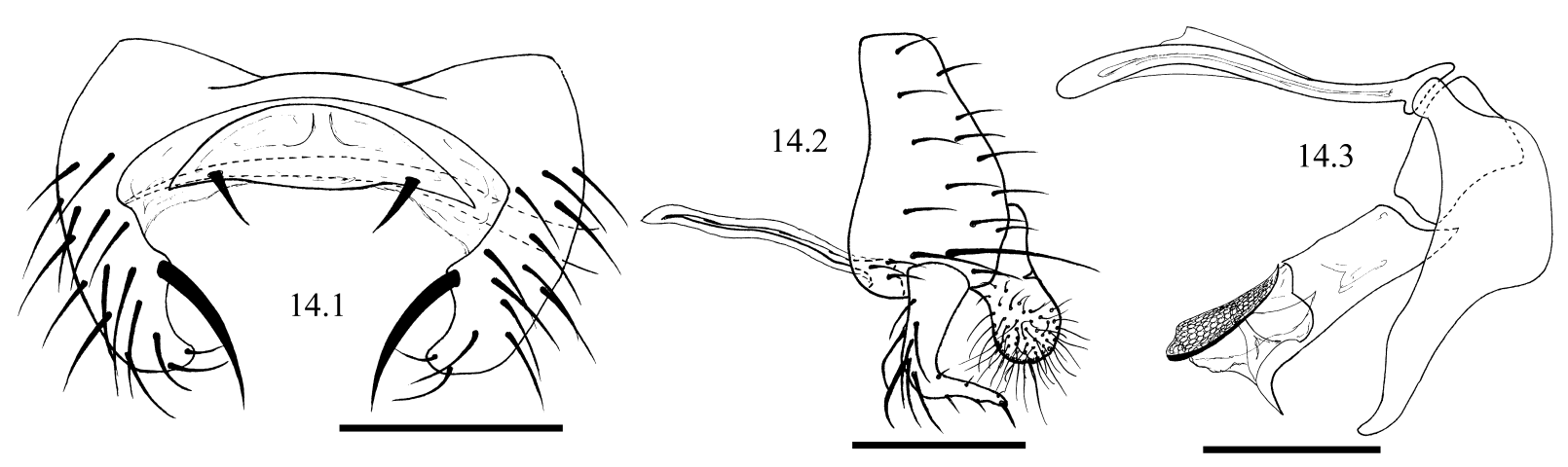

Figs 14.1-14.3. Chespiritos anguineus sp. n., holotype male abdominal structures. 14.1 - S5, ventral; 14.2 - terminalia, lateral; 14.3 aedeagus and associated structures, lateral. Scale bars: $0.20 \mathrm{~mm}$. 


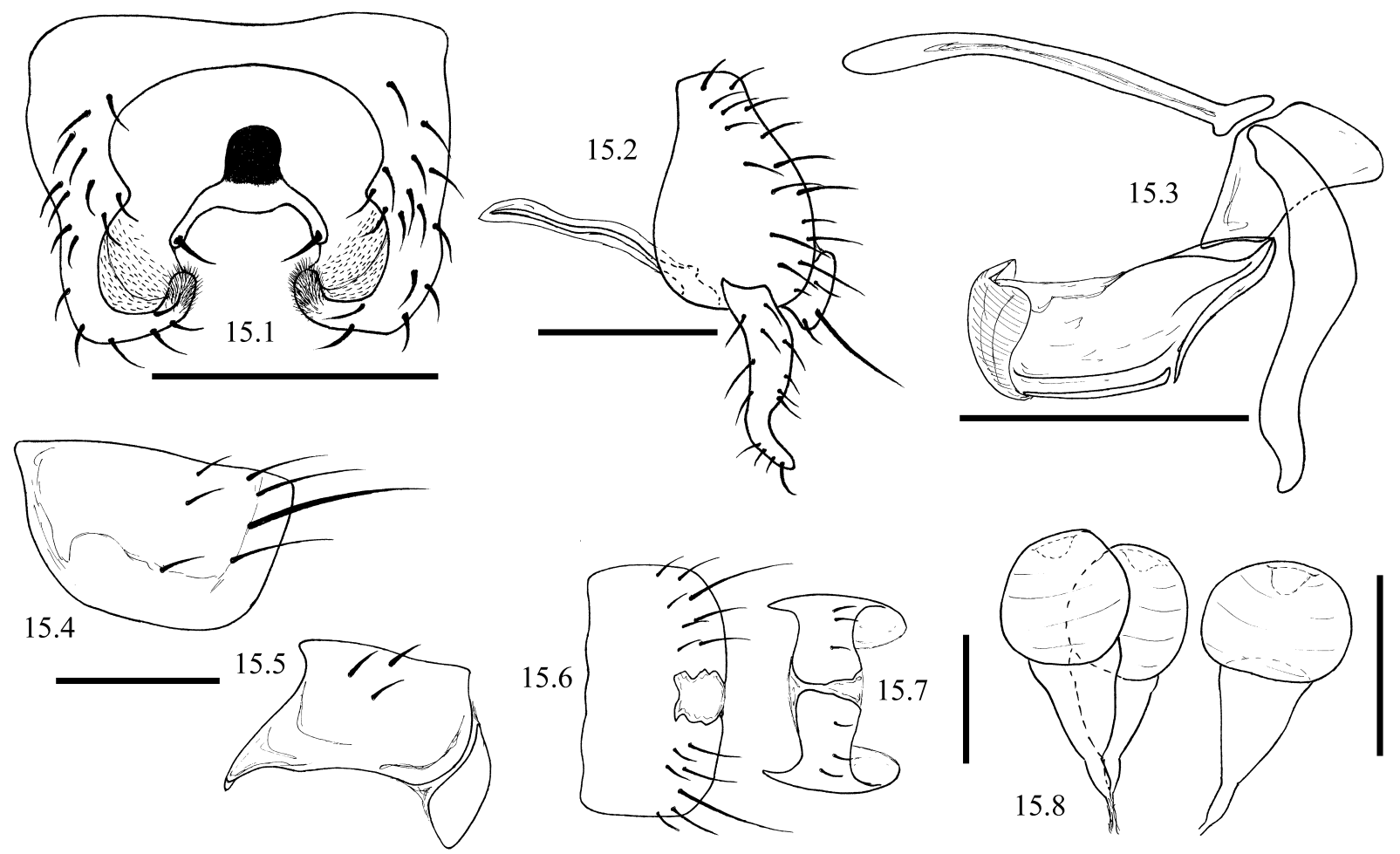

Figs 15.1-15.8. Chespiritos pervadens, male (paratype) and female abdominal structures. 15.1 - male S5, ventral; 15.2 - terminalia, lateral; 15.3 - aedeagus and associated structures, lateral; 15.4 - female T7, lateral; 15.5 - female T8, lateral; 15.6 - female T7, dorsal; 15.7 - female T8, dorsal; 15.8 - spermathecae. Scale bars: $0.20 \mathrm{~mm}$ except spermathecae $(0.10 \mathrm{~mm})$.

margin and distinctly narrowed near mid length. Basiphallus rectangular; epiphallus small, triangular and directed posteriorly. Distiphallus with basal half heavily sclerotized and tubular, apical half semi-membranous with a broad, scoop-like, apicodorsally reticulated dorsal lobe and a distinctly curved ventral lobe, connected laterally via a membranous sheet.

Female unknown.

Type material. Holotype: BOLIVIA: La Paz: $23 \mathrm{~km} \mathrm{NE}$ Caranavi, roadside/stream, sweep, 14.iv.2001, S.A. Marshall, debu00165456 (ð, CBFC).

Type locality. Bolivia, La Paz Department, $23 \mathrm{~km}$ NE Caranavi.

Etymology. This name refers to the very large setae on the posterolateral lobes of the fifth sternite, which resemble the fangs of a snake (Latin 'anguineus': having the appearance of a snake).

Distribution. This species is known only from its type locality in Bolivia.

\section{Chespiritos pervadens Roháček \& Buck 2003}

(Figs 15.1-15.8)

Chespiritos pervadens Roháček \& Buck, 2003: 45; Marshall et al., 2011: 238.

\section{Description}

Body length. Males $2.2-2.7 \mathrm{~mm}$, females $2.5-2.8 \mathrm{~mm}$.

General. Eye height $\sim 2.5 \times$ genal height. Mid femur with ventral row of 5 setae on proximal quarter. Distance between crossveins dm-cu and $\mathrm{r}-\mathrm{m} \sim 2.5 \times$ length of $\mathrm{dm}-\mathrm{cu}$.

Male abdomen. S5 with 2 large, narrow, long-setose posterolateral lobes which curl inwards; apices of lobes with dense patch of setulae, lobes connected via membranous sheet with patch of dense microtrichia; S5 medially short, length $\sim 0.14 \times$ width. Medial connecting sclerite stout, anterior section heavily sclerotized, posteriorly bifurcated with a pair of stout setae; hidden under posterior edge of S5. Epandrium uniformly long-setose. Cercus pad-like. Surstylus narrow, long-setose, apical third angled posteriorly. Postgonite long, narrow and sinuate. Basiphallus elongate, triangular; epiphallus small, rounded and directed posteriorly. Distiphallus with basal half heavily sclerotized and tubular, apical half membranous and tubular with an elongate ventral sclerite supporting a large, scoop-like, ventral lobe which curves upwards, resembling a pitcher plant.

Female abdomen. T7 with 6 pairs of smaller setae and 1 pair of larger posterolateral setae; width $\sim 1.0 \times$ width of T3; posteromedial notch large, squared, extending anteriorly $\sim 0.40 \times$ length of $\mathrm{T} 7$, posterior width $\sim 0.16 \times$ width of T7; anterolateral lobe absent. T8 with 3 pairs of smaller setae and narrow, desclerotized medial band; anterolateral lobe elongate, triangular and connected to T8, posterolateral lobe large, triangular and separated from T8. Apical bulb of spermathecae stout, spherical and weakly grooved, apically invaginated, slightly shorter than smooth, elongate basal bulbs.

Type material. Holotype: BRAZIL: Santa Catarina: Nova Teutonia, $27^{\circ} 11^{\prime} 00^{\prime \prime} \mathrm{S}, 52^{\circ} 23^{\prime} 00^{\prime \prime} \mathrm{W}, 300-500 \mathrm{~m}$, xi.1962, F. Plaumann $(\AA, \mathrm{CNCI})$. Paratypes: SPAIN: Canary Islands: Isla Gomera, El Cedro, 26.viii.-2.ix.1992, 1100 m, laurel forest, flight-intercept trap, S. \& J. Peck (1⿵人, 1ㅇ, DEBU); La Palma, Caldera de Taburiente National Park, Barranco de Las Traves, 


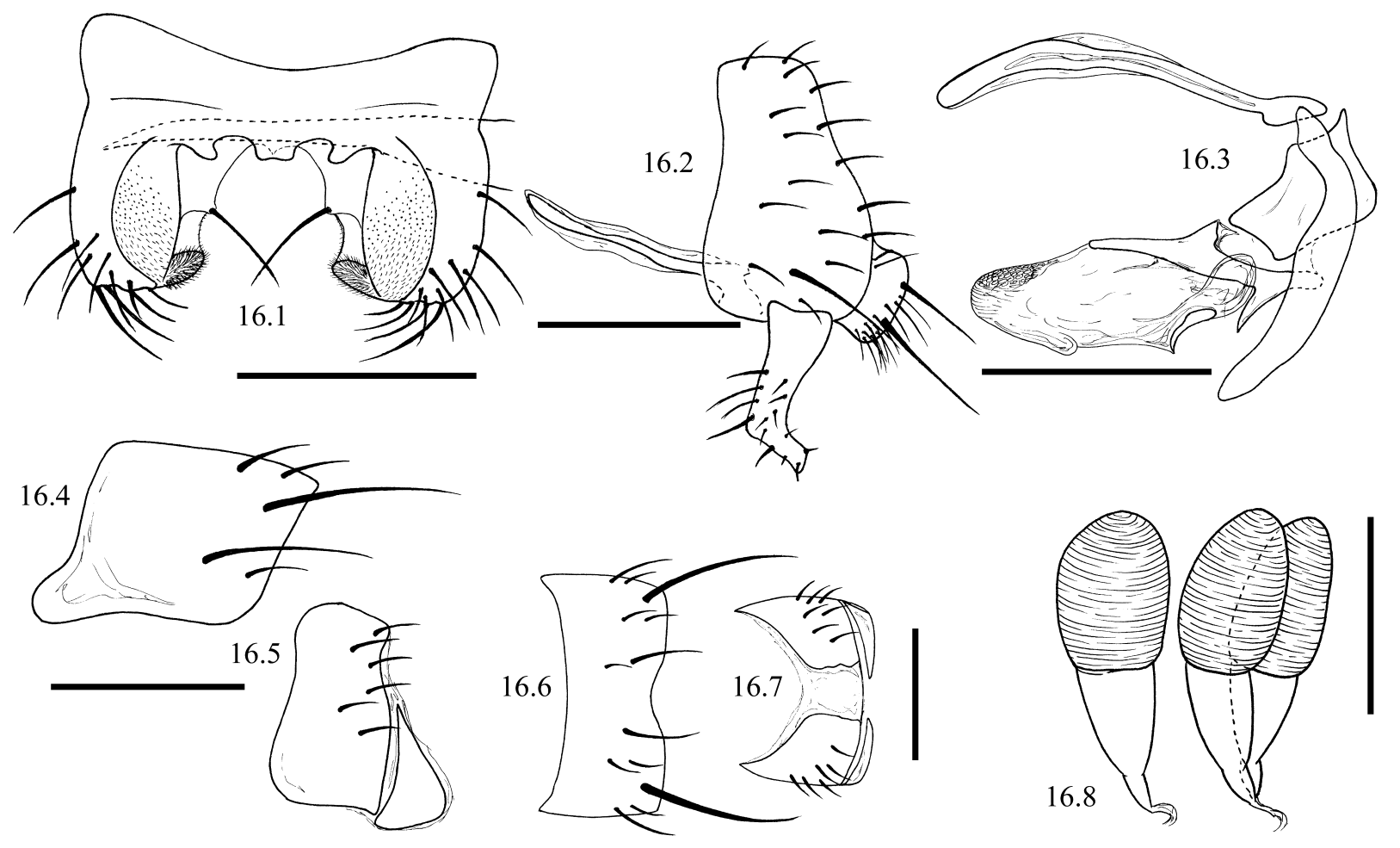

Figs 16.1-16.8. Chespiritos attenboroughi sp. n., male (holotype) and female abdominal structures. 16.1 - male S5, ventral; 16.2 - terminalia, lateral; 16.3 - aedeagus and associated structures, lateral; 16.4 - female T7, lateral; 16.5 - female T8, lateral; 16.6 - female T7, dorsal; 16.7 - female T8, dorsal; 16.8 - spermathecae. Scale bars: $0.20 \mathrm{~mm}$ except spermathecae $(0.10 \mathrm{~mm})$.

1068 m, Malaise trap, 10.-17.viii.1999, T. Domingo-Quero (1ㅇ, MNMS); La Palma, Caldera de Taburiente National Park, Playa de Taburiente, $750 \mathrm{~m}$, yellow trap, 20.ix.-5.x.1999, T. DomingoQuero (1ठ, MNMS).

Distribution. This species is known from Brazil as well as the Canary Islands.

\section{Chespiritos attenboroughi sp. $\mathrm{n}$.}

(Figs 16.1-16.8)

ZooBank taxon LSID:

9151DA8D-68F7-41B2-8404-D1A15DFBF6C0

\section{Description}

Body length. Males 2.4-2.6 mm, females 2.7-2.9 mm.

General. Eye height $\sim 2.5 \times$ genal height. Mid femur with ventral row of 5 setae on proximal quarter. Distance between crossveins dm-cu and $\mathrm{r}-\mathrm{m} \sim 2.5 \times$ length of $\mathrm{dm}-\mathrm{cu}$.

Male abdomen. S5 with 3 small posteromedial lobes and 1 pair of large, broad, long-setose, semi-membranous posterolateral lobes, each with a small, densely-microtrichose dorsoapical lobe, membranous part of lobes with dense microtrichia; S5 medially short, length $\sim 0.20 \times$ width. Epandrium uniformly long-setose with a large ventrolateral setae. Cercus pad-like, protuberant and densely-setose. Surstylus narrow, long-setose with apical third bent posteriorly. Postgonite long, narrow and decurved. Basiphallus rectangular, slightly curved; epiphallus reduced to a rounded lobe. Distiphallus with basal fifth heavily sclerotized and tubular with sclerotization extending dorsally to about mid length, apical four-fifth membranous and tubular with small ventral sclerite near base and large, scoop-like, apicodorsally reticulated lobe.

Female abdomen. T7 with 4 pairs of smaller setae and 2 pairs of larger posterolateral and medial setae; width $\sim 1.25 \times$ width of T3; posteromedial notch very small, extending anteriorly $\sim 0.13 \times$ length of $\mathrm{T} 7$, posterior width $\sim 0.33 \times$ width of $\mathrm{T} 7$; anterolateral lobe small and rounded. T8 medially desclerotized with 6 pairs of small lateral setae and wide, desclerotized medial band; anterolateral lobe small, triangular and connected to T8, posterolateral lobe large, triangular and separated from T8. Apical bulb of spermathecae elongate and grooved, equal to length of smooth, elongate basal bulb.

Type material. Holotype: ARGENTINA: Salta: El Rey National Park, $1000 \mathrm{~m}$, Pozo Verde trail, km 7, Malaise flight intercept trap, yungas forest, 5.-15.xii.1987, S. \& J. Peck (ô, DEBU). Paratypes: ARGENTINA: same data as holotype (1 $1 \hat{\sigma}^{\wedge}$, 4ㅇ, DEBU).

Type locality. Argentina, Salta Province, El Rey National Park.

Etymology. This name is in honour of Sir David Attenborough, whose programs about, and advocacy of, wildlife conservation helped inspire the first author to pursue a career in the biological sciences.

Distribution. This species is known only from its type locality in Argentina.

\section{Chespiritos peckorum sp. $\mathbf{n}$.}

(Figs 17.1-17.3)

ZooBank taxon LSID:

BA8B0FD7-2F01-4E93-86DC-21996D593E6C 

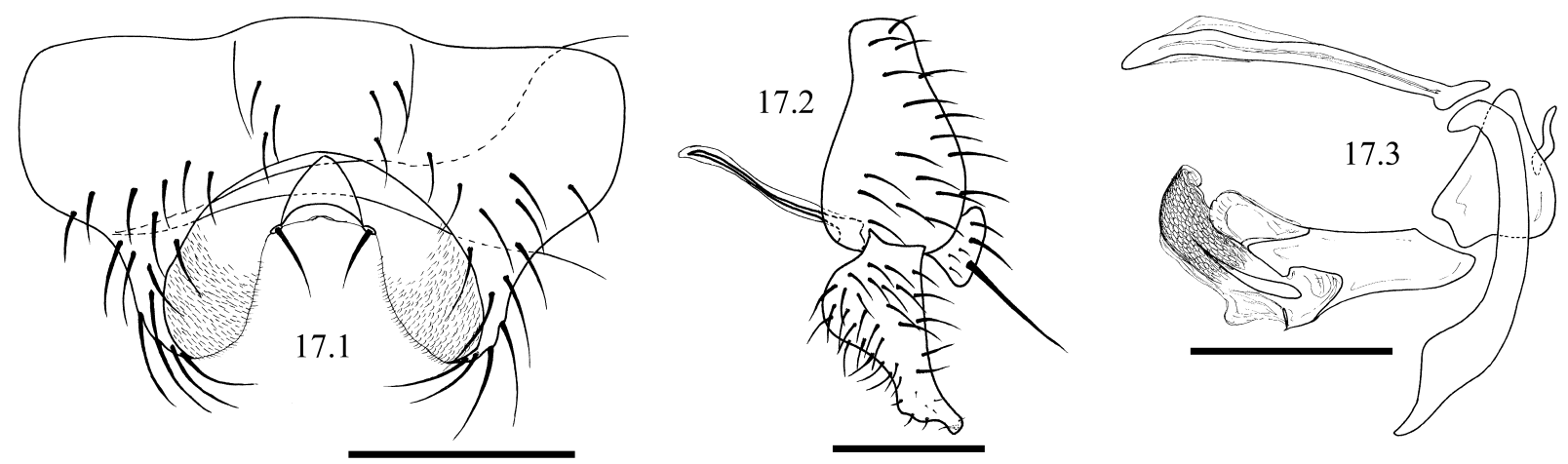

Figs 17.1-17.3. Chespiritos peckorum sp. n., holotype male abdominal structures. 17.1 - S5, ventral; 17.2 - terminalia, lateral; $17.3-$ aedeagus and associated structures, lateral. Scale bars: $0.20 \mathrm{~mm}$.

\section{Description}

Body length. Male $2.2 \mathrm{~mm}$.

General. Eye height $\sim 2.0 \times$ genal height. Mid femur with ventral row of 4 setae on proximal quarter. Distance between crossveins dm-cu and $\mathrm{r}-\mathrm{m} \sim 2.5 \times$ length of $\mathrm{dm}-\mathrm{cu}$.

Male abdomen. S5 complex, main body setose with a pair of elongate, long-setose posterolateral lobes, lobes connected via a membranous sheet with dense microtrichia; S5 medially short, length $\sim 0.25 \times$ width. Medial connecting sclerite stout, triangular, broadly emarginate posteriorly with a pair of strong setae. Epandrium uniformly long-setose. Cercus with a small ventromedial lobe. Surstylus large, long-setose and sock-like. Postgonite dark, decurved, apex broadly truncate with a small distal lobe curling inwards. Basiphallus large, triangular; epiphallus broad, rounded and directed posteriorly. Distiphallus with basal half heavily sclerotized and tubular, apical half semimembranous with 2 dorsolateral lobes and an elongate ventral sclerite supporting a large, scoop-like, reticulated ventral lobe.

Female unknown.

Type material. Holotype: ECUADOR: Pichincha: Rio Palenque, $47 \mathrm{~km} \mathrm{~S}$ Santo Domingo, $250 \mathrm{~m}$, rainforest Malaise flight intercept trap, 5.v.-25.vii.1985, S. \& J. Peck (ठ̊, DEBU).

Type locality. Ecuador, Pichincha Province, Rio Palenque, 47 km S Santo Domingo.

Etymology. This name is in honour of Dr. Stewart B. Peck and Dr. Jarmila Kukalová-Peck who provided us with insect trap samples that include nine Chespiritos species, including this one.

Distribution. This species is known only from its type locality in Ecuador.

\section{Chespiritos sindecimus Marshall 2000}

(Figs 18.1-18.8)

Chespiritos sindecimus Marshall, 2000: 609; Roháček et al., 2001: 134.

\section{Description}

Body length. Males $1.7-2.4 \mathrm{~mm}$, females $1.9-2.8 \mathrm{~mm}$.

General. Eye height $\sim 2.5 \times$ genal height. Mid femur with ventral row of 4 setae on proximal quarter. Distance between crossveins dm-cu and $\mathrm{r}-\mathrm{m} \sim 2.5 \times$ length of $\mathrm{dm}-\mathrm{cu}$.

Male abdomen. S5 complex, main body bare with a large medial cleft bordered by a pair of small, bare postero- medial lobes and a pair of elongate, long-setose posterolateral lobes; S5 medially short, length $\sim 0.25 \times$ width. Medial connecting sclerite stout, posteriorly bifurcated with a pair of strong setae; may be hidden under posterior edge of S5. Epandrium large, uniformly long-setose with a long ventrolateral seta. Cercus pad-like. Surstylus large, leaf-like, anterior edge with a row of stout setae along entire length and a lateral patch of finer setulae in basal half. Postgonite dark, decurved, apex broadly rounded and serrated with a small tooth-like projection on apicoventral edge. Basiphallus elongate, rectangular; epiphallus large, rounded and directed ventrally. Distiphallus very large, basal two-thirds heavily sclerotized and tubular, apical third semi-membranous with 2 large sclerites supporting 3 lobes which form a tube, ventral lobes ventrolaterally reticulated.

Female abdomen. T7 with 3 pairs of smaller setae and 1 pair of larger posterolateral and 1 pair of medial setae; width $\sim 1.25 \times$ width of $\mathrm{T} 3$; posteromedial notch triangular, extending anteriorly $\sim 0.25 \times$ length of $\mathrm{T} 7$, posterior width $\sim 0.20 \times$ width of $\mathrm{T} 7$; anterolateral lobe large and rounded, angled downwards. T8 with 5 pairs of smaller setae and large, desclerotized posteromedial triangle; anterolateral lobe highly reduced and connected to T8, posterolateral lobe large, triangular and separated from T8. Apical bulb of spermathecae stout, spherical and grooved, equal to length of smooth, stout basal bulb.

Type material. Holotype: COSTA RICA: Cartago: Río Macho, La Esperanza, El Guarco $(8 \mathrm{~km}$ from km 61 Interamerican Highway), 2400 m, LN-188200, 549800, Hoja Tapanti, in bromeliads on ground, 1.vi.1998, S.A. Marshall (ð, MNCR). Paratypes: same data as holotype $(3 \hat{\jmath}, 4 q, \mathrm{MNCR}, \mathrm{DEBU})$. Other material examined: COSTA RICA: Cartago: Paraíso, Ta-

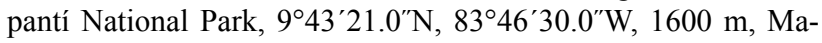
laise trap, 20.-27.i.2012, Proyecto ZADBI (1今̄, MNCR); Paraíso, Tapantí-Macizo de La Muerte National Park, 943'21.0”N, $83^{\circ} 46^{\prime} 30.0^{\prime \prime} \mathrm{W}, 1600 \mathrm{~m}$, Malaise trap, 18.-28.x.2012, Proyecto ZADBI (2^, MNCR); Río Macho Forest Reserve, $2200 \mathrm{~m}$, on downed bromeliads, 10.x.1999, S.A. Marshall (1 $ᄋ$, DEBU); Heredia: Vara Blanca, $6 \mathrm{~km}$ ENE, $10^{\circ} 11^{\prime} 00 .{ }^{\prime \prime} \mathrm{N}, 84^{\circ} 07^{\prime} 00.0^{\prime \prime} \mathrm{W}, 2000$ m, 15.ii.2002, no collector data (1 $\left.\hat{O}^{\lambda}, \mathrm{DEBU}\right)$; San José: Moravia, Zurquí de Moravia, $10^{\circ} 02^{\prime} 58.0^{\prime \prime} \mathrm{N}, 84^{\circ} 00^{\prime} 57.0^{\prime \prime} \mathrm{W}, 1600 \mathrm{~m}$, hand collected, 23.ix.2012, Proyecto ZADBI (1 + , MNCR); Moravia, Zurquí de Moravia, Tower path, $10^{\circ} 02^{\prime} 58.0^{\prime \prime} \mathrm{N}, 84^{\circ} 00^{\prime} 57.0^{\prime \prime} \mathrm{W}$, $1600 \mathrm{~m}$, Malaise trap \#1, 0 m, 30.viii.-6.ix.2013, Proyecto ZADBI (1 9, MNCR); Moravia, Zurquí de Moravia, Tower path, 


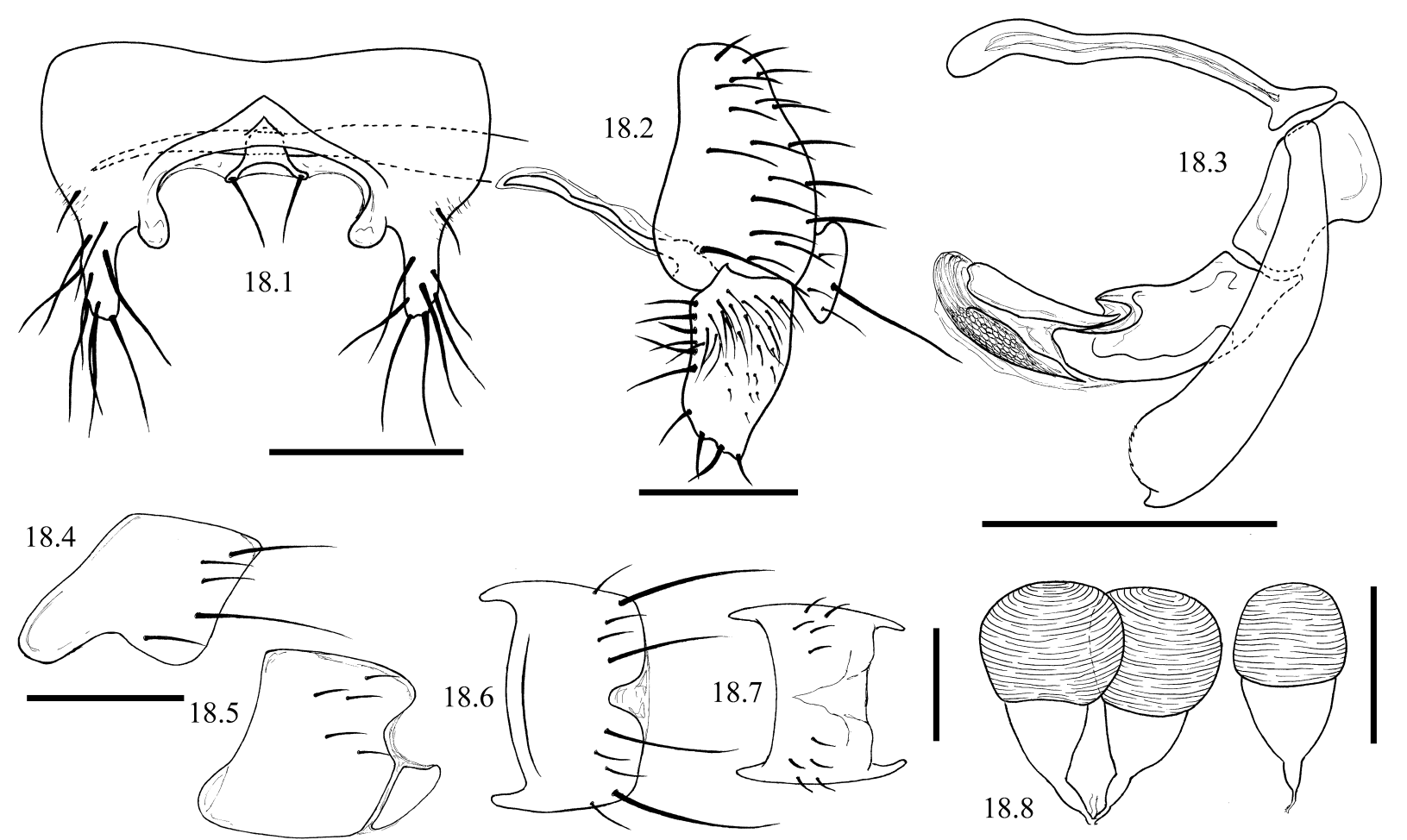

Figs 18.1-18.8. Chespiritos sindecimus, male (paratype) and female abdominal structures. 18.1 - male S5, ventral; 18.2 - terminalia, lateral; 18.3 - aedeagus and associated structures, lateral; 18.4 - female T7, lateral; 18.5 - female T8, lateral; 18.6 - female T7, dorsal; 18.7 - female T8, dorsal; 18.8 - spermathecae. Scale bars: $0.20 \mathrm{~mm}$ except spermathecae $(0.10 \mathrm{~mm})$.

$10^{\circ} 02^{\prime} 58.0^{\prime \prime} \mathrm{N}, 84^{\circ} 00^{\prime} 57.0^{\prime \prime} \mathrm{W}, 1600 \mathrm{~m}$, Malaise trap \#1, $0 \mathrm{~m}$, 26.iv.-3.v.2013, Proyecto ZADBI (1+, MNCR); Moravia, Zurquí de Moravia, Tower path, $10^{\circ} 02^{\prime} 58.0^{\prime \prime} \mathrm{N}, 84^{\circ} 00^{\prime} 57.0^{\prime \prime} \mathrm{W}, 1600$ $\mathrm{m}$, Malaise trap \#1, 0 m, 6.-13.ix.2013, Proyecto ZADBI (3ㅇ, MNCR).

Distribution. This species is known only from Costa Rica.

\section{Chespiritos hojagrande sp. $\mathrm{n}$.}

(Figs 19.1-19.3)

ZooBank taxon LSID:

311AAE48-2D28-4327-8E66-41B055089ADB

\section{Description}

Body length. Males 2.2-2.4 mm.

General. Eye height $\sim 2.0 \times$ genal height. Mid femur with ventral row of 4 setae on proximal quarter. Distance between crossveins dm-cu and r-m $\sim 2.0 \times$ length of dm-cu.

Male abdomen. S5 complex, main body uniformly long-setose with a large medial cleft bordered by a pair of small, bare posteromedial lobes flanking and pair of elongate, long-setose posterolateral lobes, posterolateral lobes connected via a membranous sheet with dense microtrichia; S5 medially short, length $\sim 0.20 \times$ width. Medial connecting sclerite stout, medially constricted with a pair of apicolateral projections, each terminating in a strong seta. Epandrium uniformly long-setose with a ventrolateral pair of large setae. Cercus pad-like. Surstylus very large, leaflike with a row of 5 or 6 stout setae along anterior edge and finer setae laterally; apex with a small lateral lobe. Postgonite dark, decurved, apically broad and slightly emarginated. Basiphallus elongate, rectangular; epiphallus broad, rounded and directed posteriorly. Distiphallus with basal half heavily sclerotized and tubular, apical half semi-membranous with a sclerotized dorsal lobe and 2 membranous, laterally reticulated ventrolateral lobes supported ventrally by elongate, tapered sclerites which curl upwards apically.

Female unknown.

Type material. Holotype: MEXICO: San Luis Potosí: $20 \mathrm{~km}$ W Xilitla, $1600 \mathrm{~m}$, cloud forest, flight intercept trap, 12.vi.-6. viii.1983, S. \& J. Peck (ô, DEBU). Paratypes: COSTA RICA: Puntarenas: Monteverde Biological Station, $1500 \mathrm{~m}$, white pans in kitchen compost, 13.vi.2000, M. Buck (1ठ, MNCR). MEXI$\mathrm{CO}$ : same data as holotype (1 $\left.\partial^{\lambda}, \mathrm{DEBU}\right)$.

Type locality. Mexico, San Luis Potosí State, $20 \mathrm{~km} \mathrm{~W} \mathrm{Xilitla.}$

Etymology. The species name reflects the similarity between the surstylus and a large leaf (Spanish 'hoja': leaf, sheet, blade; Spanish 'grande': large, big, great).

Distribution. This species is known from Costa Rica and Mexico.

\section{Chespiritos coronatus sp. $\mathbf{n}$.}

(Figs 20.1-20.8)

ZooBank taxon LSID:

13DB63BC-DDED-4BB2-B9E3-7A9DD2002360

\section{Description}

Body length. Males 1.2-2.1 mm, females 1.9-2.4 mm.

General. Eye height $\sim 2.5 \times$ genal height. Mid femur with ventral row of 4 setae on proximal quarter. Distance between crossveins dm-cu and $\mathrm{r}-\mathrm{m} \sim 3.0 \times$ length of $\mathrm{dm}-\mathrm{cu}$.

Male abdomen. S5 with a small medial cleft bordered by a pair of small, bare posteromedial lobes and a pair of small, triangular, long-setose posterolateral lobes; S5 


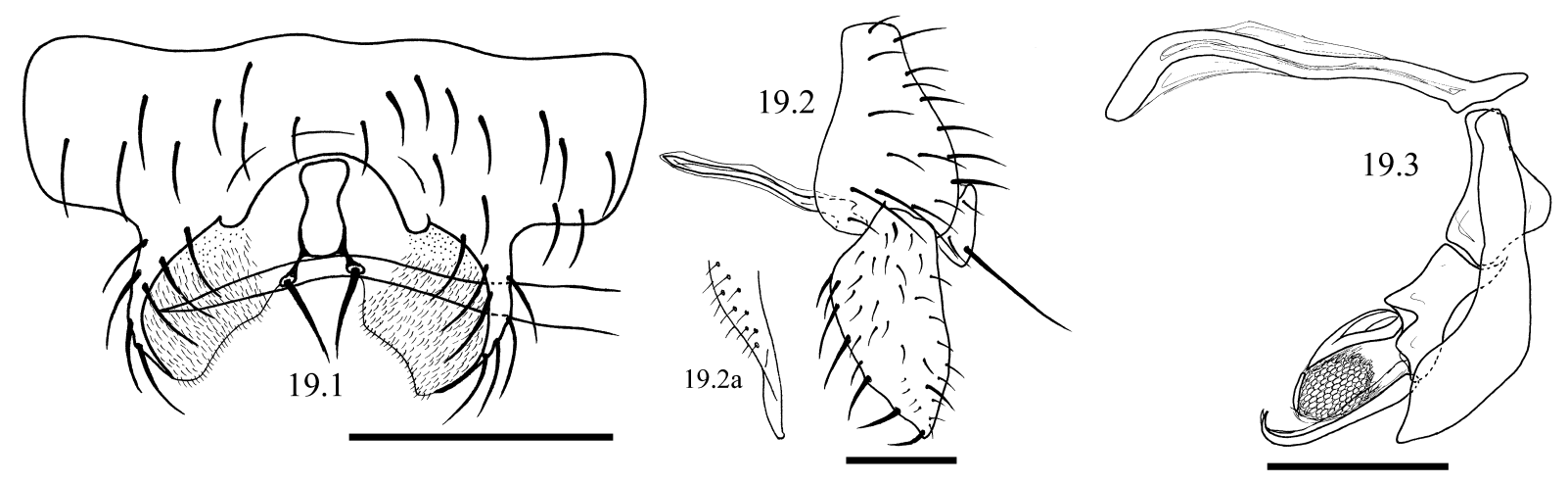

Figs 19.1-19.3. Chespiritos hojagrande sp. n., holotype male abdominal structures. 19.1 - S5, ventral; 19.2 - terminalia, lateral; $19.2 \mathrm{a}-$ surstylus, posterior; 19.3 - aedeagus and associated structures, lateral. Scale bars: $0.20 \mathrm{~mm}$.

medially short, length $\sim 0.16 \times$ width. Medial connecting sclerite small, elongate with a pair of short mediolateral projections, each terminating in a stout seta; hidden under posterior edge of S5. Epandrium uniformly long-setose with larger posterolateral seta. Cercus pad-like. Surstylus very large, leaf-like, anterior edge with a shallow emargination across middle half; anterior edge with a row of long setae along anterior edge and finer setae laterally. Postgonite dark, elongate, sinuate along anterior margin with apex broad, ventrally flattened and angled anteriorly. Basiphallus elongate, triangular; epiphallus small, square and directed posteroventrally. Distiphallus with basal two-third heavily sclerotized and tubular, apical third semi-membranous with sclerotized dorsal lobe and 2 membranous, laterally reticulated ventrolateral lobes supported ventrally by elongate, tapered sclerites that curl upwards apically.
Female abdomen. T7 with 4 pairs of smaller setae and 1 pair of larger posterolateral setae; width $\sim 1.25 \times$ width of T3; posteromedial notch semicircular, extending anteriorly $\sim 0.25 \times$ length of $\mathrm{T} 7$, posterior width $\sim 0.16 \times$ width of T7; anterolateral lobe small, angled anteriorly. T8 with 5 pairs of smaller setae and small, desclerotized posteromedial triangle; anterolateral lobe triangular and connected to $\mathrm{T} 8$, posterolateral lobe rectangular and separated from T8. Apical bulb of spermathecae stout, spherical and grooved, $\sim$ equal to length of smooth, triangular basal bulb.

Type material. Holotype: COSTA RICA: Heredia: La Selva, $10^{\circ} 25^{\prime} 48.00^{\prime \prime} \mathrm{N}, 84^{\circ} 01^{\prime} 12.00^{\prime \prime} \mathrm{W}$, Malaise trap at intersection of Sendero Oriental and Sendero Holdridge, 8.-15.v.1989, B.

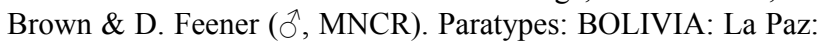
Caranavi, $10 \mathrm{~km} \mathrm{NW}$, road to Entel tower, $1400 \mathrm{~m}, 15^{\circ} 46^{\prime} 35^{\prime \prime} \mathrm{S}$, $67^{\circ} 35^{\prime} 48^{\prime \prime} \mathrm{W}, 13 . i x .2001$, S.A. Marshall (1 $\left.{ }^{\top}, \mathrm{CBFC}\right)$; Chulumani, Apa Apa Reserve, $2000 \mathrm{~m}, 1^{\circ} 21^{\prime} 15^{\prime \prime} \mathrm{S}, 6^{\circ} 30^{\prime} 21^{\prime \prime} \mathrm{W}$, pans

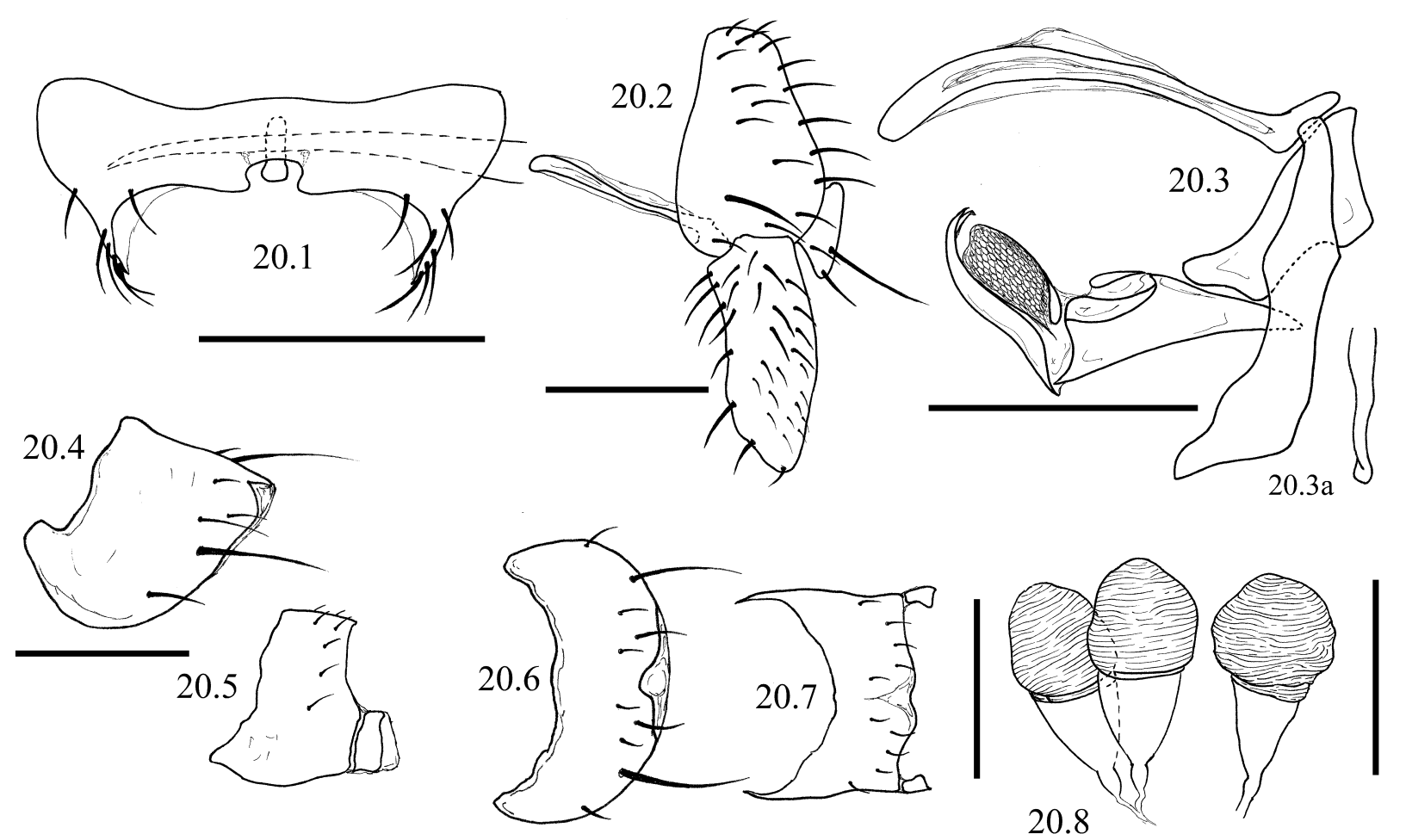

Figs 20.1-20.8. Chespiritos coronatus sp. n., male (holotype) and female abdominal structures. 20.1 - male S5, ventral; 20.2 - terminalia, lateral; 20.3 - aedeagus and associated structures, lateral; 20.3a - postgonite, posterior; 20.4 - female T7, lateral; 20.5 - female T8, lateral; 20.6 - female T7, dorsal; 20.7 - female T8, dorsal; 20.8 - spermathecae. Scale bars: $0.20 \mathrm{~mm}$ except spermathecae $(0.10 \mathrm{~mm})$. 


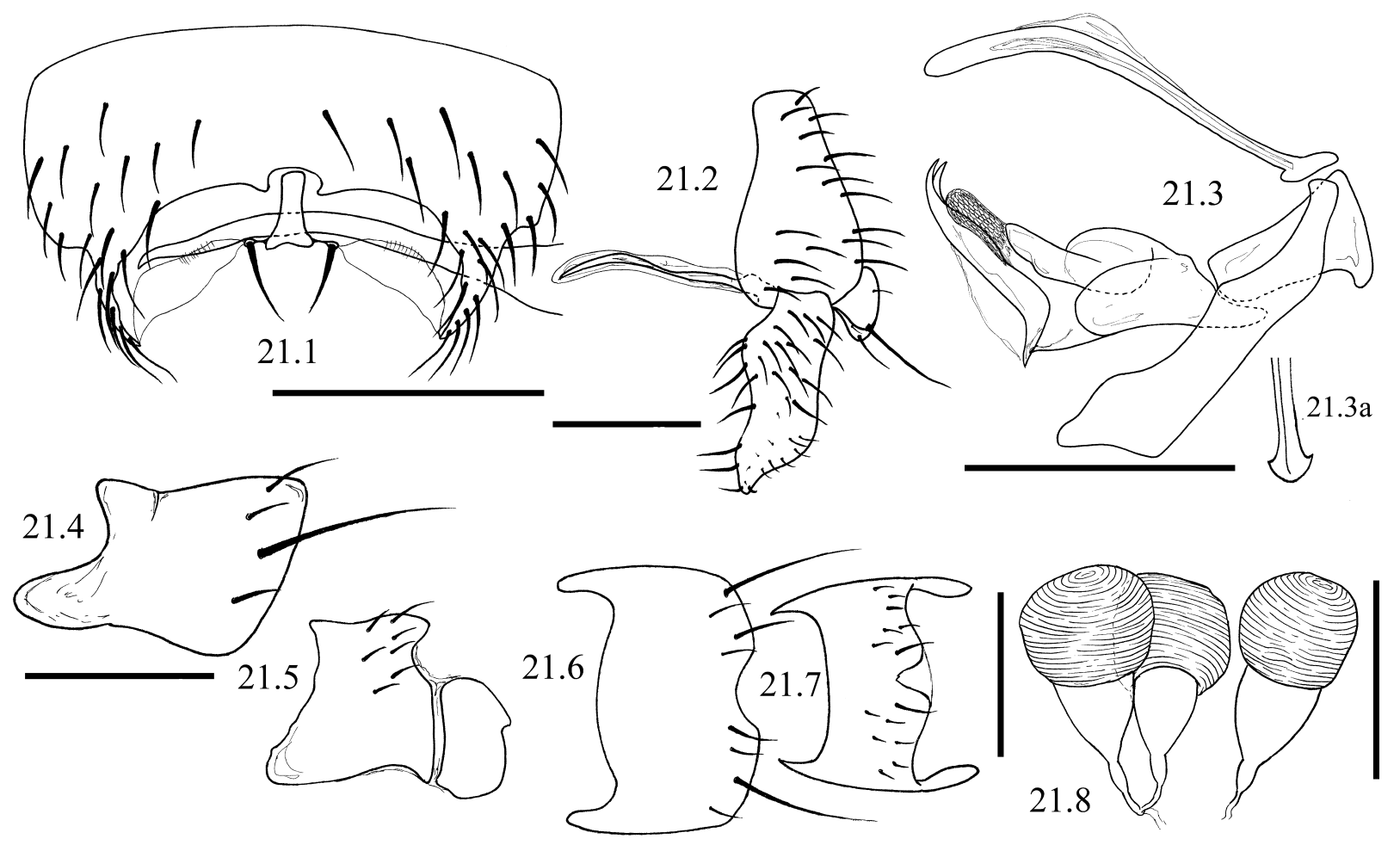

Figs 21.1-21.8. Chespiritos lepustergum sp. n., male (holotype) and female abdominal structures. 21.1 - male S5, ventral; 21.2 - terminalia, lateral; 21.3 - aedeagus and associated structures, lateral; 21.3a - postgonite, posterior; 21.4 - female T7, lateral; 21.5 - female T8, lateral; 21.6 - female T7, dorsal; 21.7 - female T8, dorsal; 21.8 - spermathecae. Scale bars: $0.20 \mathrm{~mm}$ except spermathecae $(0.10 \mathrm{~mm})$.

in compost, 1.-3.iv.2001, S.A. Marshall (1 $\hat{O}^{\Uparrow}$, DEBU); Heath River Wildlife Centre, $21 \mathrm{~km}$ SSW Puerto Heath, $12^{\circ} 40^{\prime} 0.00^{\prime \prime} \mathrm{S}$, $68^{\circ} 42^{\prime} 0.00^{\prime \prime} \mathrm{W}, 29 . v i .-12 . v .2007$, S.M. Paiero $\left(3 \jmath^{\wedge}, 3 q\right.$, CBFC, DEBU); Heath River Wildlife Centre, $\sim 21 \mathrm{~km}$ SSW Puerto Heath, $12^{\circ} 40^{\prime} 0.00^{\prime \prime} \mathrm{S}, 68^{\circ} 42^{\prime} 0.00^{\prime \prime} \mathrm{W}$, treefall, yellow pan traps, 5.-7.v.2007, Marshall \& Kits (10̄, DEBU); Heath River Wildlife Centre, treefall, yellow pans, 5.-9.v.2007, Marshall \& Kits (10̄, CBFC). BRAZIL: Paraná: Curitiba, flight intercept trap, in woods behind Natural History Museum, 5.-9.ii.1990, S.A. Marshall (1 $\jmath^{\lambda}$, MZSP). COLOMBIA: Santander: 2 mi N Chinacota, 3000',

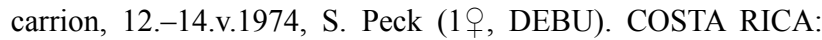
Limón: Estrella Valley, Pandora, Malaise trap, 28.iii.1984, G.V. Manley (2犬̂, DEBU). ECUADOR: Napo: Jatun Sacha Biological Reserve, $6 \mathrm{~km}$ E Misahualli, $450 \mathrm{~m}$, compost, yellow pans, $1^{\circ} 04^{\prime} 0.00^{\prime \prime} \mathrm{S}, 77^{\circ} 37^{\prime} 0.00^{\prime \prime} \mathrm{W}, 1$.-2.v.2002, M. Buck (3今े, QCAZ, DEBU); Jatun Sacha Biological Reserve, $6 \mathrm{~km}$ E Misahualli, 450 $\mathrm{m}$, landslide in forest, Malaise trap, $1^{\circ} 04^{\prime} 0.00^{\prime \prime} \mathrm{S}, 77^{\circ} 37^{\prime} 0.00^{\prime \prime} \mathrm{W}$, 30.iv.-7.v.2002, Buck et al. (19, DEBU); vicinity Yasuni National Park, Tiputini Biodiversity Station, Malaise trap, 14.-19. ii.1998. D.C. Darling (1ð̂, 1ㅇ, QCAZ, DEBU); Yasuni National Park, Yasuni Research Station, rainforest Malaise trap, 3.-20. xi.1998, Pape \& Viklund (1ð̂, DEBU); Pichincha: Rio Palenque Station, 47 km S Santo Domingo, 160 m, mal.hd.1* (Malaise trap in primary forest), lowland rainforest, 30.iv.-5.v.1987, L. Coote \& B. Brown (1 $\hat{\jmath}$, DEBU); Rio Palenque, $47 \mathrm{~km}$ S Santo Domingo, $250 \mathrm{~m}$, rainforest Malaise flight intercept trap, 5.v.-25. vii.1985, S. \& J. Peck (14우, QCAZ, DEBU). TRINIDAD: Saint George County, U. Santa Cruz, Gasparillo, Malaise trap, "gr/for. edge", 15.xi.1987, R. Borneo (19, DEBU).

Type locality. Costa Rica, Heredia Province, La Selva.

Etymology. The species name refers to the fifth sternite, which resemble a royal crown (Latin 'coronatus': crowned, garlanded).

Distribution. This widespread species is known from southern Brazil to Central America.

\section{Chespiritos lepustergum sp. $\mathrm{n}$.}

(Figs 21.1-21.8)

ZooBank taxon LSID:

E6BBC45D-F291-4DFD-A776-F3EDD4C6A5D7

\section{Description}

Body length. Males 1.9-2.7 mm, females 2.1-2.7.

General. Eye height $\sim 2.5 \times$ genal height. Mid femur with ventral row of 4 setae on proximal quarter. Distance between crossveins dm-cu and $\mathrm{r}-\mathrm{m} \sim 2.5 \times$ length of $\mathrm{dm}-\mathrm{cu}$.

Male abdomen. S5 with scattered setae and a small medial cleft bordered by a pair of very small, bare posteromedial lobes and a pair of long-setose posterolateral lobes; S5 medially short, length $\sim 0.25 \times$ width. Medial connecting sclerite short, posterior half gradually expanded and slightly emarginate with a pair of short, lateral projections, each terminating in a strong seta. Epandrium uniformly longsetose. Cercus pad-like. Surstylus very large, leaf-like, anterior edge with a shallow emargination across middle half; anterior edge with long setae along entire length and smaller setae laterally. Postgonite dark, elongate, sinuate along anterior margin with apex broad, ventrally flattened with two ridges extending laterally, forming a rubber-stamp-like shape. Basiphallus elongate, rectangular; epiphallus small, triangular and directed posteroventrally. Distiphallus with basal two-thirds large, heavily sclerotized and tubular, apical third semi-membranous with a sclerotized dorsal lobe and 2 membranous, laterally reticulated ventrolateral lobes supported by elongate, tapered sclerites which curl upwards apically. 

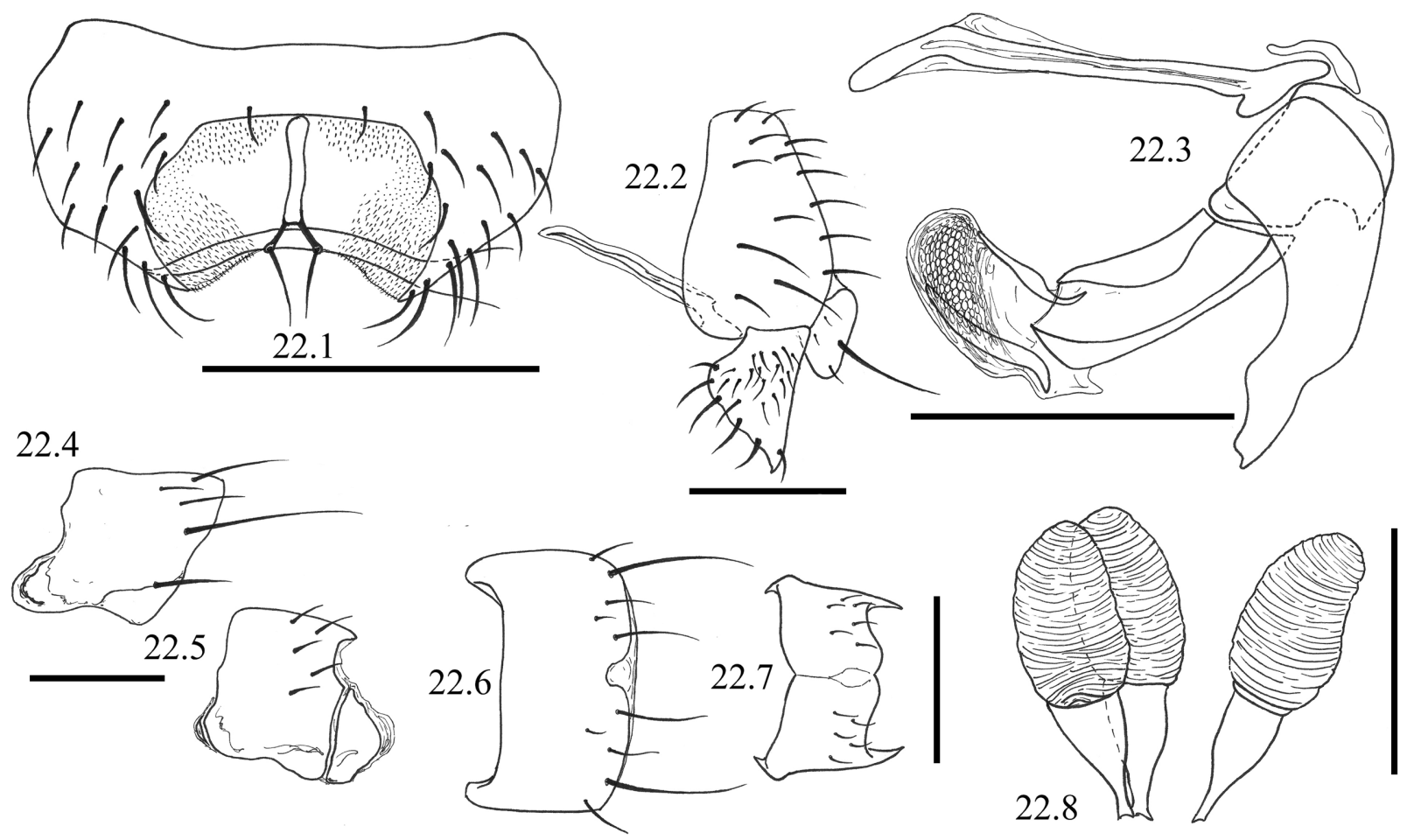

Figs 22.1-22.8. Chespiritos ganchopico sp. n., male (holotype) and female abdominal structures. 22.1 - male S5, ventral; 22.2 - terminalia, lateral; 22.3 - aedeagus and associated structures, lateral; 22.4 - female T7, lateral; 22.5 - female T8, lateral; 22.6 - female T7, dorsal; 22.7 - female T8, dorsal; 22.8 - spermathecae. Scale bars: $0.20 \mathrm{~mm}$ except spermathecae $(0.10 \mathrm{~mm})$.

Female abdomen. T7 with 3 pairs of smaller setae and 1 pair of larger posterolateral setae; width $\sim 1.25 \times$ width of T3; posteromedial notch semicircular, extending anteriorly $\sim 0.16 \times$ length of $\mathrm{T} 7$, posterior width $\sim 0.33 \times$ width of T7; anterolateral lobe rounded, angled anteriorly. T8 with 7 pairs of smaller setae and small, desclerotized posteromedial triangle; anterolateral lobe broadly triangular and connected to T8, posterolateral lobe large, rectangular and separated from T8. Apical bulb of spermathecae stout, spherical and grooved, equal to length of smooth, stout basal bulb.

Type material. Holotype: COSTA RICA: Heredia: $16 \mathrm{~km} \mathrm{SSE}$ La Virgen, $1050-1150 \mathrm{~m}, 10^{\circ} 16^{\prime} 0.00^{\prime \prime} \mathrm{N}, 84^{\circ} 5^{\prime} 0.00^{\prime \prime} \mathrm{W}$, transect, 9.iv.2001, (no collector given), debu00229462 (ठ, MNCR). Paratypes: COSTA RICA: Guanacaste: Guanacaste Conserva-

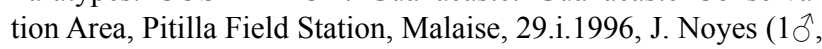
1ㅇ, MNCR, DEBU); Heredia: Braulio Carrillo National Park, $10^{\circ} 10^{\prime} 0.00^{\prime \prime} \mathrm{N}, 84^{\circ} 07^{\prime} 0.00^{\prime \prime} \mathrm{W}, 500 \mathrm{~m}, 10 . \mathrm{iv} .1985$, H. Goulet \& L. Masner $(1 \hat{\jmath}, 3$ ㅇ, DEBU); Limón: Estrella Valley, Pandora, Malaise trap, 28.iii.1984, G.V. Manley (1へ̂, DEBU); same data as holotype (1ठ, MNCR). VENEZUELA: Mérida: Mérida "Fac.

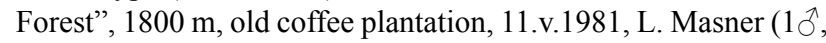
DEBU).

Type locality. Costa Rica, Heredia Province, 16 km SSE La Virgen.

Etymology. This name refers to the very long surstyli, which cause the posterior view of the terminalia to resemble the head of a rabbit (Latin 'lepus': rabbit, hare; Latin 'tergum': back, rear).

Distribution. This species is known from Costa Rica and Venezuela.

\section{Chespiritos ganchopico sp. $\mathrm{n}$.}

(Figs 22.1-22.8)

\section{ZooBank taxon LSID:}

98690FA3-FB65-40DC-91A4-7E74B71BBD37

\section{Description}

Body length. Males $1.8-2.1 \mathrm{~mm}$, females $1.7-2.3 \mathrm{~mm}$.

General. Eye height $\sim 2.5 \times$ genal height. Mid femur with ventral row of 5 setae on proximal quarter. Distance between crossveins dm-cu and r-m $\sim 2.5 \times$ length of $\mathrm{dm}-\mathrm{cu}$.

Male abdomen. S5 setose with a pair of broad, triangular, long-setose posterolateral lobes, lobes connected via a membranous sheet with dense microtrichia; S5 medially short, length $\sim 0.20 \times$ width. Medial connecting sclerite elongate, apically bifurcated with a pair of setae. Epandrium uniformly long-setose. Cercus pad-like. Surstylus triangular with a row of 5 or 6 stout setae along anterior edge and a large discal patch of finer setae. Postgonite dark, tapered, sinuate, apex with slightly emarginate. Basiphallus elongate, rectangular; epiphallus large, decurved and directed posteroventrally. Distiphallus with basal twothirds heavily sclerotized and tubular, apical third semimembranous with 3 scoop-like, apicolaterally reticulated lobes which form a tube.

Female abdomen. T7 with 3 pairs of smaller setae and 2 pairs of larger posterolateral and medial setae; width $\sim 1.25 \times$ width of T3; posteromedial notch small, square, extending anteriorly $\sim 0.16 \times$ length of $\mathrm{T} 7$, posterior width $\sim 0.11 \times$ width of 77 ; anterolateral lobe large and rounded, angled downwards. T8 with 5 pairs of small setae and posteromedial emargination; anterolateral lobe highly reduced and separated from T8, posterolateral lobe large, triangular and separated from T8. Apical bulb of spermathecae elon- 


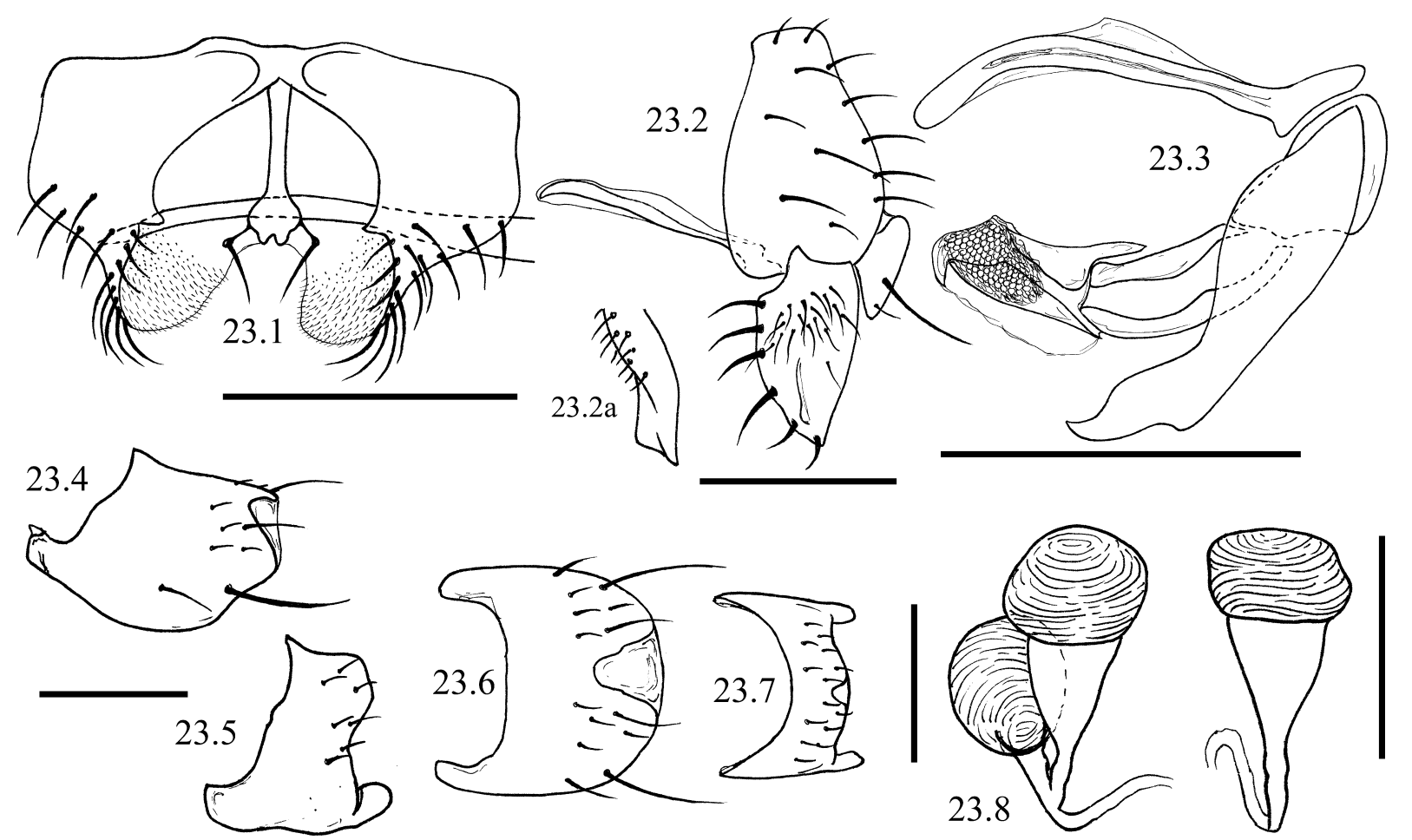

Figs 23.1-23.8. Chespiritos extendido sp. n., male (holotype) and female abdominal structures. 23.1 - male S5, ventral; 23.2 - terminalia, lateral; 23.2a - surstylus, posterior; 23.3 - aedeagus and associated structures, lateral; 23.4 - female T7, lateral; 23.5 - female T8, lateral; 23.6 - female T7, dorsal; 23.7 - female T8, dorsal; 23.8 - spermathecae. Scale bars: $0.20 \mathrm{~mm}$ except spermathecae $(0.10 \mathrm{~mm})$.

gate, conical and grooved, slightly longer than smooth, elongate basal bulb.

Type material. Holotype: ARGENTINA: Jujuy: Mirador, Calilegua National Park, $600 \mathrm{~m}$, forest Malaise flight intercept trap, 18.-28.xii.1987, S. \& J. Peck (ô, DEBU). Paratypes. ARGENTINA: Jujuy: Calilegua National Park, Aguas Negras, 500 $\mathrm{m}$, gallery forest, Malaise flight intercept trap, 18.-28.xii.1987, S. \& J. Peck (1ㅇ, DEBU); Calilegua National Park, Aguas Negras, $550 \mathrm{~m}$, campground forest, Malaise flight intercept trap, 18.-28. xii.1987, S. \& J. Peck (4仓̂, 1 +, DEBU); Calilegua National Park, El Cortadeval Km 6, 800 m, forest Malaise, 18.-28.xii.1987, S. \& J. Peck (1ㅇ, DEBU); Calilegua National Park, Estaca El Cero, $900 \mathrm{~m}$, forest carrion trap, 19.-20.xii.1987, S. \& J. Peck (1우, DEBU); Calilegua National Park, Estación El Cero, 900 m, forest Malaise flight intercept trap, 18.-28.xii.1987, S. \& J. Peck (8今̄, 7ㅇ, DEBU); Calilegua National Park, Mirador, 600 m, forest carrion trap, 18.-28.xii.1987, S. \& J. Peck (29, DEBU); Misiónes: $5 \mathrm{~km}$ E Puerto Iguazo, dense forest, small Malaise head, 1.-6.ii.1992, S.A. Marshall (3ㅇ, DEBU); Salta: El Rey National Park, 1000 m, Pozo Verde Trail, km 7, Malaise flight intercept trap, yungas forest, 5.-15.xii.1987, S. \& J. Peck (1 人َ, DEBU); El Rey National Park, Rio La Sala, 900 m, Malaise flight intercept trap, open stream side in forest, 5.-10.xii.1987, S. \& J. Peck (1 $\hat{\jmath}$, DEBU); Rosario de Lerma, "INESALT" yard Malaise, 16.-28. ii.1992, S.A. Marshall (3 + , DEBU); same data as holotype (7 7 , 15 9 , DEBU); BOLIVIA: La Paz: Heath River Wildlife Centre, $\sim 21 \mathrm{~km}$ SSW Puerto Heath, $12^{\circ} 40^{\prime} 0.00^{\prime \prime} \mathrm{S}, 68^{\circ} 42^{\prime} 0.00^{\prime \prime} \mathrm{W}$, 29.iv.12.v.2007, S.M. Paiero (4 $\left.{ }^{\wedge}, \mathrm{CBFC}, \mathrm{DEBU}\right)$. ECUADOR: Ex. Heliconia, Rio Palenque, 27.ii.1979, S.A. Marshall $(7 \hat{\jmath}, 5$, QCAZ, DEBU). PANAMA: Colón: Gamboa, Pipeline Road, reared from Heliconia mariae, vii.1967, W. \& M. Wirth $(1 \AA, 3$, USNM). TOBAGO: $10 \mathrm{~km}$ NE Roxborough, Gilpin Trail, 400$500 \mathrm{~m}$, mountain rainforest, flight intercept trap, 26.-31.vii.1993,
S. \& J. Peck (1을 DEBU); 10 km NE Roxborough, Gilpin Trail, $450 \mathrm{~m}$, rainforest, carrion traps, 26.-31.vi.1993, S. \& J. Peck,

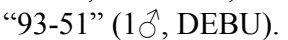

Type locality. Argentina, Jujuy Province, Calilegua National Park.

Etymology. This name refers to the shape of the surstylus which resembles the hooked beak of a bird of prey (Spanish 'gancho': hook, claw; Spanish 'pico': beak, peak, lip).

Distribution. This species is recorded from Argentina, Bolivia, Ecuador, Panama and Tobago.

\section{Chespiritos extendido sp. $\mathbf{n}$.}

(Figs 1, 2.1-2.2, 3.1-3.2, 5.1-5.2, 23.1-23.8)

ZooBank taxon LSID:

846D62A3-E4D1-4024-B915-EBD5DE80EFA2

\section{Description}

Body length. Males 1.5-2.3 mm, females 1.4-2.4 mm.

General. Eye height $\sim 2.5 \times$ genal height. Mid femur with ventral row of 5 setae on proximal quarter. Distance between crossveins $\mathrm{dm}-\mathrm{cu}$ and $\mathrm{r}-\mathrm{m} \sim 2.0-2.5 \times$ length of dm-cu.

Male abdomen. S5 with large central cleft bordered by a pair of small, bare posteromedial lobes and pair of large, long-setose posterolateral lobes, lobes connected via a membranous sheet with dense microtrichia; S5 short, length $\sim 0.20 \times$ width. Medial connecting sclerite elongate, posterior quarter bulbous with two small apical lobes, 'bulb' with a pair of lateral projections, each terminating with a seta. Epandrium uniformly long-setose. Cercus padlike. Surstylus leaf-like with a row of 5 stout setae along 

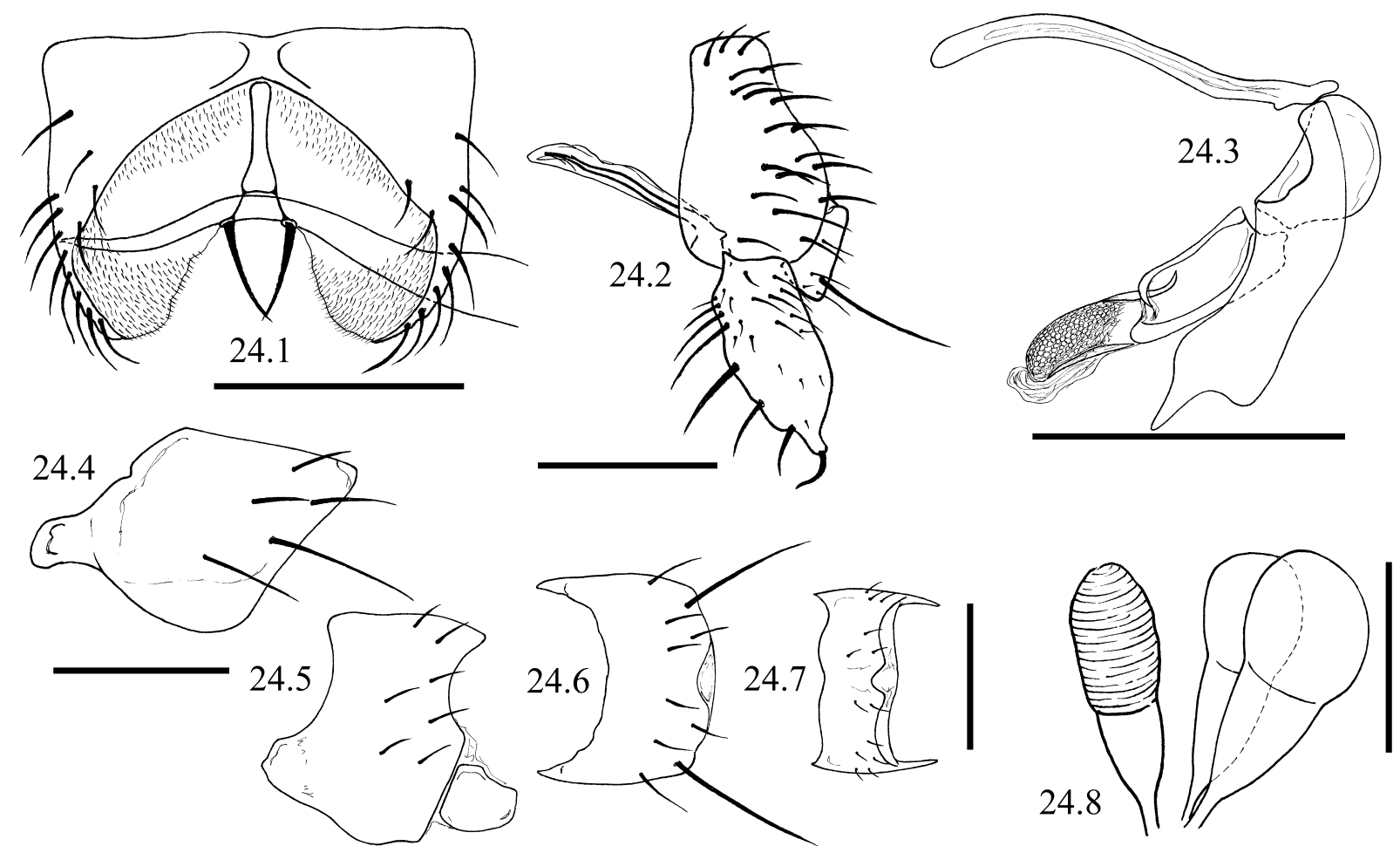

Figs 24.1-24.8. Chespiritos paraiso sp. n., male (holotype) and female abdominal structures. 24.1 - male S5, ventral; 24.2 - terminalia, lateral; 24.3 - aedeagus and associated structures, lateral; 24.4 - female T7, lateral; 24.5 - female T8, lateral; 24.6 - female T7, dorsal; 24.7 - female T8, dorsal; 24.8 - spermathecae. Scale bars: $0.20 \mathrm{~mm}$ except spermathecae $(0.10 \mathrm{~mm})$.

anterior edge and a patch of finer setae laterally; distal half with a large triangular lateral lobe. Postgonite dark, elongate, sinuate along anterior margin with a small preapical posterior notch. Basiphallus elongate, rectangular; epiphallus small, rounded and directed posteroventrally. Distiphallus with basal half heavily sclerotized and tubular, apical half semi-membranous with 2 large sclerites supporting 3 scoop-like, apicolaterally reticulated lobes which form a tube.

Female abdomen. T7 with 5 pairs of smaller setae and 2 pairs of larger posterolateral and medial setae; width $\sim 2.0 \times$ width of T3; posteromedial notch large, triangular, extending anteriorly $\sim 0.5 \times$ length of $\mathrm{T} 7$, posterior width $\sim 0.33 \times$ width of T7; anterolateral lobe rectangular, angled anteriorly. T8 with 8 pairs of smaller setae and small, desclerotized posteromedial notch; anterolateral lobe rectangular and connected to T8, posterolateral lobe semicircular and semi-separated from T8. Apical bulb of spermathecae stout, spherical and grooved, $\sim 0.67 \times$ length of smooth, elongate basal bulb.

Type material. Holotype: VENEZUELA: Aragua: Maracay, Rancho Grande cloud forest, $1200 \mathrm{~m}$, flight intercept trap, 1.-10. viii.1987, Bordon \& Peck (ô, DEBU). Paratypes: BOLIVIA: La Paz: Chulumani, Apa Apa Reserve, 2000 m, 16²1'15"S,

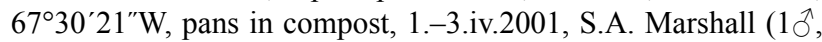
CBFC). COLOMBIA: Cundinamarca: Finca Bella Vista, near Sasaima, 7.vi.1965, P.R. \& D.L. Craig (1우 CNCI). COSTA RICA: Limón: Estrella Valley, Pandora, flight intercept trap, 16.iii.1984, G.V. Manley \& H.F. Howden (1 $\left.\partial^{\top}, \mathrm{CNCI}\right)$; Estrella Valley, Pandora, Malaise, 28.iii.1984, G.V. Manley (10̄, CNCI). ECUADOR: Galapagos Islands: Santa Cruz, 4 km N Bellavista
Media Luna, $620 \mathrm{~m}$, Miconia Zone, flight intercept trap, 14.v.-13.

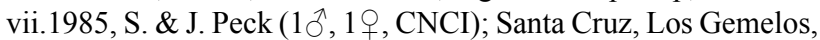
$600 \mathrm{~m}$, Scalesia forest, dung trap, 31.i.-4.ii.1989, B.J. Sinclair (1 $\widehat{\jmath}, \mathrm{CNCI})$; Pichincha: Maquipucuna Biological Reserve, 1200 m, compost pan traps, 27.-29.x.1999, S.A. Marshall, (1今̄, 2 ㅇ, QCAZ); Rio Palenque, $47 \mathrm{~km} \mathrm{~S}$ Santa Domingo, $250 \mathrm{~m}$, rainforest Malaise flight intercept trap, 5.v.-25.vii.1985, S. \& J. Peck (1 $\hat{\jmath}, \mathrm{DEBU})$. MEXICO: Oaxaca: 26 km E Valle Nacional, km 71, $1220 \mathrm{~m}$, tropical forest, flight intercept trap, 25.vi.-2.viii.1983, S. \& J. Peck (1ठ̂, DEBU); San Luis Potosí: 1600 m, 20 km W Xilitla, cloud forest, flight intercept trap, 12.vi.-6.viii.1983, S. \& J. Peck $(1 \hat{\jmath}, 1$ q DEBU). PANAMA: Bocas del Toro, Almirante, 24.iii.1959, H.S. Dybas (2ð, 3 + , FMNH). VENEZUELA: Aragua: Henri Pittier National Park, Rancho Grande Biological Station, v.1998, Ashe, Brooks \& Hanley (10, 1오, DEBU); Henri Pittier National Park, Rancho Grande Portochuelo Pass, 9.iv.1994, "MN Am", L. Masner (1ठ̄, DEBU); Romancho Grande, La Cumbre cloud forest, $1500 \mathrm{~m}$, flight intercept trap, 1.-10.viii.1987, Bordon \& Peck (1亏े,1ㅇ, DEBU); Táchira: 20 km NE San Cristobal, 1200 m, dung trap, 18.-22.v.1974, S. Peck $(2 \widehat{\jmath}, 1$,, $\mathrm{DEBU}) ; 38 \mathrm{~km}$ NE San Cristobal, $2100 \mathrm{~m}$, carrion trap, 18.-20.vi.1974, S. Peck (2ㅇ, DEBU).

Type locality. Venezuela, Aragua State, Maracay, Rancho Grande cloud forest.

Etymology. This name refers to the wide range of this species, which is known from more countries than any other species of Chespiritos (Spanish 'extendido': widespread, spread out, extended).

Distribution. This species is the most widespread species of Chespiritos, having been collected from Bolivia, Colombia, Costa Rica, Ecuador (including the Galapagos Islands), Mexico, Panama and Venezuela. 


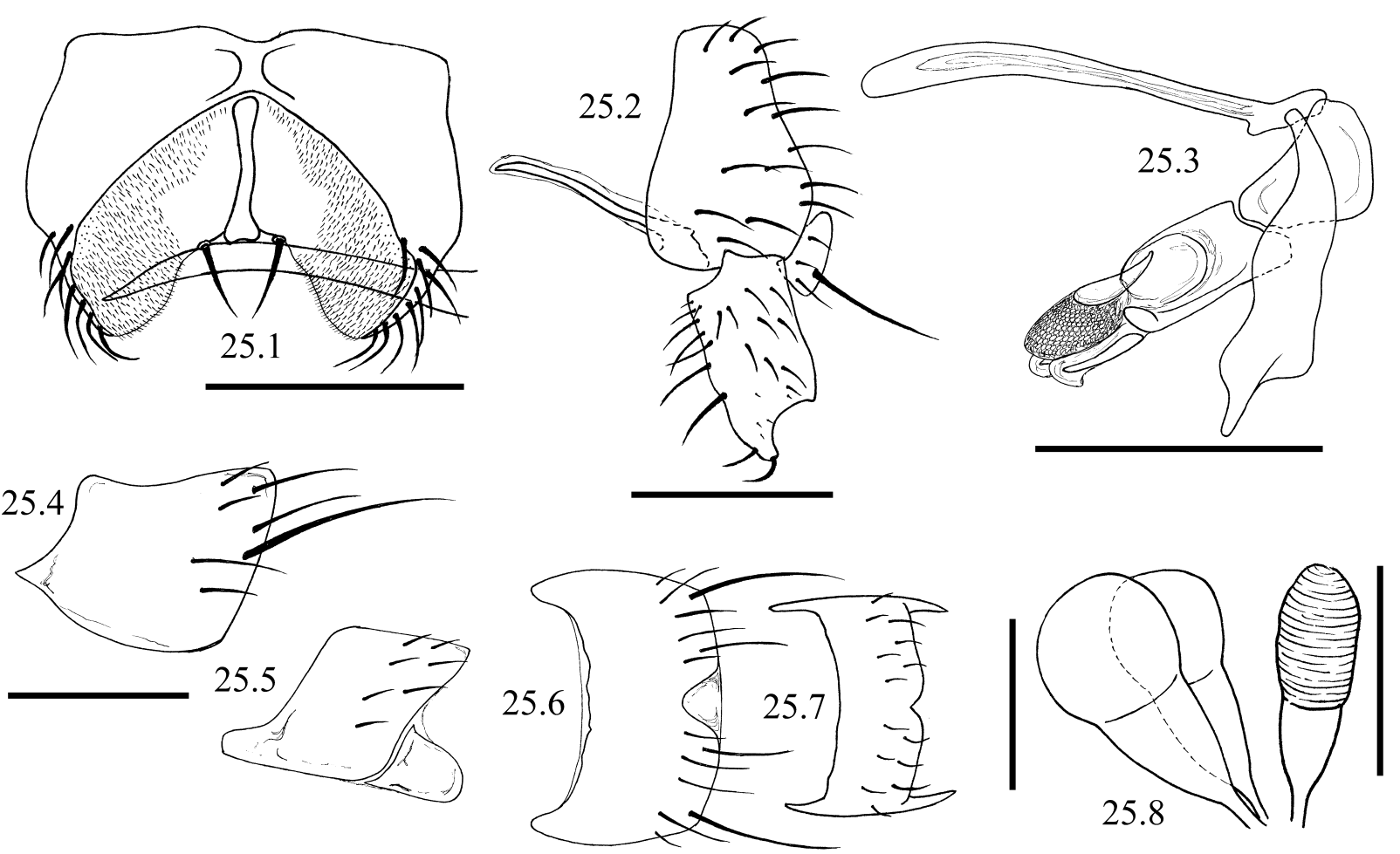

Figs 25.1-25.8. Chespiritos bolanosi sp. n., male (holotype) and female abdominal structures. 25.1 - male S5, ventral; 25.2 - terminalia, lateral; 25.3 - aedeagus and associated structures, lateral; 25.4 - female T7, lateral; 25.5 - female T8, lateral; 25.6 - female T7, dorsal; 25.7 - female T8, dorsal; 25.8 - spermathecae. Scale bars: $0.20 \mathrm{~mm}$ except spermathecae $(0.10 \mathrm{~mm})$.

\section{Chespiritos paraiso sp. $\mathbf{n}$.}

(Figs 24.1-24.8)

\section{ZooBank taxon LSID:}

38391718-8399-44F1-BE23-2433F7FDC5A0

\section{Description}

Body length. Males $1.8-2.3 \mathrm{~mm}$, females $1.5-2.2 \mathrm{~mm}$.

General. Eye height $\sim 2.5 \times$ genal height. Mid femur with ventral row of 3 setae on proximal quarter. Distance between crossveins dm-cu and $\mathrm{r}-\mathrm{m} \sim 2.5 \times$ length of $\mathrm{dm}-\mathrm{cu}$.

Male abdomen. S5 with a pair of large, apically incurved long-setose posterolateral lobes, lobes connected via a membranous sheet with dense microtrichia; S5 medially short, length $\sim 0.14 \times$ width. Medial connecting sclerite elongate, posterior third expanded with a pair of apicolateral projections, each terminating in a strong seta. Epandrium uniformly long-setose. Cercus with a slight ventral indentation. Surstylus rectangular with a row of stout setae along anterior edge and a small patch of finer discal setae near the base; basal two-thirds of posterior edge straight, apical third gently sinuate; apex with a small, blade-like lobe. Postgonite dark, broad, sinuate along anterior margin with a large anterobasal notch, dramatically narrowed about apical quarter. Basiphallus semicircular; epiphallus reduced to a rounded lobe. Distiphallus large, with basal half heavily sclerotized and tubular, apical half semi-membranous with 2 elongate sclerites supporting 3 scoop-like, apicolaterally reticulated lobes which form a tube.

Female abdomen. T7 with 4 pairs of smaller setae and 1 pair of larger posterolateral setae; width $\sim 1.25 \times$ that of
T3; posteromedial notch small, semicircular, extending anteriorly $\sim 0.16 \times$ length of T7, posterior width $\sim 0.33 \times$ width of T7; anterolateral lobe large and rectangular, angled anteriorly. T8 with 7 pairs of smaller setae and a small, desclerotized posteromedial cleft; anterolateral lobe small, rounded and connected to T8, posterolateral lobe small, rectangular and separated from T8. Apical bulb of single spermatheca elongate, conical and grooved, slightly longer than length of smooth, tapered basal bulb; apical bulbs of paired spermathecae stout, spherical and smooth, slightly less than length of smooth, elongate basal bulbs.

Type material. Holotype: DOMINICAN REPUBLIC: Barahona: $7 \mathrm{~km}$ NW Paraiso, $200 \mathrm{~m}$, rainforest remnant, flight intercept trap, 27.xi.-4.xii.1991, Masner \& Peck (ð, DEBU). Paratypes: DOMINICAN REPUBLIC: Barahona: 7 km NW Paraiso, $200 \mathrm{~m}$, rainforest remnant, fungus on logs, 27.xi.1991, S. \& J. Peck (10̂, DEBU); La Cienega, flight intercept trap, 11.-22.i.1989, S.A. Marshall \& J.E. Swann (1 $\widehat{\partial}$, DEBU); Pedernales: $28 \mathrm{~km}$ N Cabo Rojo, $760 \mathrm{~m}$ evergreen dry forest, flight intercept trap, 27.xi.-3.

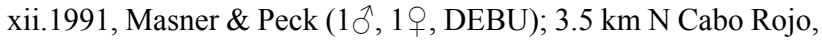
$18^{\circ} 06^{\prime} 0.00^{\prime \prime} \mathrm{N}, 71^{\circ} 38^{\prime} 0.00^{\prime \prime} \mathrm{W}, 540 \mathrm{~m}$, deciduous forest, flight intercept trap, 19.-25.vii.1990, L. Masner, J. Rawlins \& C. Young $(1 \hat{\jmath}, 1$,, $\mathrm{FMNH})$; same data as holotype (1ठ, DEBU).

Type locality. Dominican Republic, Barahona Province, $7 \mathrm{~km}$ NW Paraiso.

Etymology. This species name is a noun in apposition based on the name of the type locality of the species, the town of Paraíso in the Dominican Republic.

Distribution. This species is only known from the Dominican Republic. 

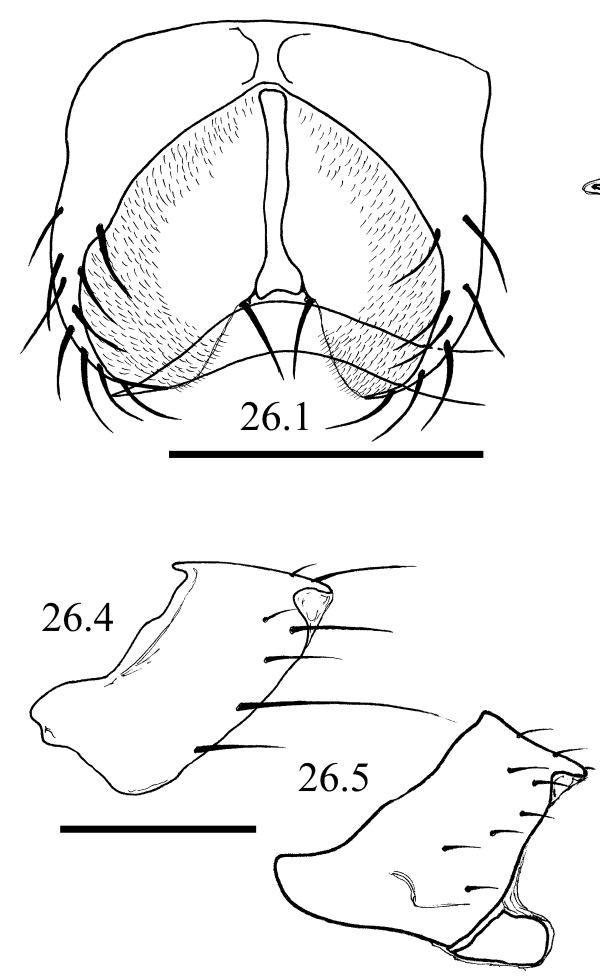

Figs 26.1-26.8. Chespiritos dolabratus sp. n., male (holotype) and female abdominal structures. 26.1 - male S5, ventral; 26.2 - terminalia, lateral; 26.3 - aedeagus and associated structures, lateral; 26.4 - female T7, lateral; 26.5 - female T8, lateral; 26.6 - female T7, dorsal; 26.7 - female T8, dorsal; 26.8 - spermathecae. Scale bars: $0.20 \mathrm{~mm}$ except spermathecae $(0.10 \mathrm{~mm})$.

\section{Chespiritos bolanosi sp. $\mathbf{n}$.}

(Figs 25.1-25.8)

ZooBank taxon LSID:

989B7F2C-0062-4264-B912-7F052206CCDB

\section{Description}

Body length. Males $1.9 \mathrm{~mm}$, females $1.9-2.0 \mathrm{~mm}$.

General. Eye height $\sim 2.5 \times$ genal height. Mid femur with ventral row of 3 setae on proximal quarter. Distance between crossveins dm-cu and $\mathrm{r}-\mathrm{m} \sim 2.0 \times$ length of $\mathrm{dm}-\mathrm{cu}$.

Male abdomen. S5 with a pair of large, apically incurved, long-setose posterolateral lobes, lobes connected via a membranous sheet with dense microtrichia; S5 medially narrow, length $\sim 0.20 \times$ width. Medial connecting sclerite elongate, slightly sinuate, posterior quarter swollen and slightly emarginate with a pair of lateral projections, each terminating in a strong seta. Epandrium uniformly longsetose. Cercus with a slight ventral indentation. Surstylus rectangular with a row of stout setae along anterior edge and a small patch of finer discal setae; posteroapical corner with a rounded emargination; apex with a small, bladelike lobe. Postgonite dark, broad, sinuate along anterior margin and gently tapered about apical fifth. Basiphallus stout, rectangular; epiphallus reduced to a rounded lobe. Distiphallus with basal half heavily sclerotized and tubular, apical half semi-membranous with 2 elongate sclerites supporting 3 scoop-like lobes; dorsal lobe reticulated.

Female abdomen. T7 with 5 pairs of smaller setae and 2 pairs of larger posterolateral and medial setae; width $\sim 1.5 \times$ width of T3; posteromedial notch triangular, extending anteriorly $\sim 0.25 \times$ length of $\mathrm{T} 7$, posterior width $\sim 0.25 \times$ width of T7; anterolateral lobe small and triangular, angled anteriorly. T8 with 7 pairs of smaller setae and a small posteromedial notch; anterolateral lobe rectangular and connected to $\mathrm{T} 8$, posterolateral lobe broadly triangular and separated from T8. Apical bulb of single spermatheca elongate, conical and grooved, slightly longer than length of smooth, elongate basal bulb; apical bulbs of paired spermathecae stout, spherical and smooth, slightly less than length of smooth, elongate basal bulbs.

Type material. Holotype: MEXICO: Veracruz: $33 \mathrm{~km} \mathrm{NE}$ Catemaco, $160 \mathrm{~m}$, Los Tuxtlas Biological Station, ravine, rainforest, flight intercept trap, 1.vii.-1.viii.1983, S. Peck (§, DEBU). Paratypes: MEXICO: Chiapas: $6.4 \mathrm{~km} \mathrm{~S}$ Palenque, $200 \mathrm{~m}$, rain forest, human dung trap, 7.-15.viii.1971, A. Newton $(1 \hat{\jmath}, 1$, DEBU); Veracruz: $33 \mathrm{~km}$ NE Catemaco, $160 \mathrm{~m}$ Los Tuxtlas Biological Station, ridge, rainforest, flight intercept trap, 1.vii.-1. viii.1983, S. Peck (1, DEBU).

Type locality. Mexico, Veracruz State, Los Tuxtlas Biological Station.

Etymology. This name is a patronym in memory of Roberto Gómez Bolaños, Mexican screenwriter, actor, comedian and creator of the character Chespirito.

Distribution. This species is known only from Mexico.

\section{Chespiritos dolabratus sp. $\mathbf{n}$.}

(Figs 26.1-26.8)

ZooBank taxon LSID:

FB866791-2947-429C-B541-A51749D53DFF

\section{Description}

Body length. Males 1.8-1.9 mm, females 1.6-1.8 mm. 


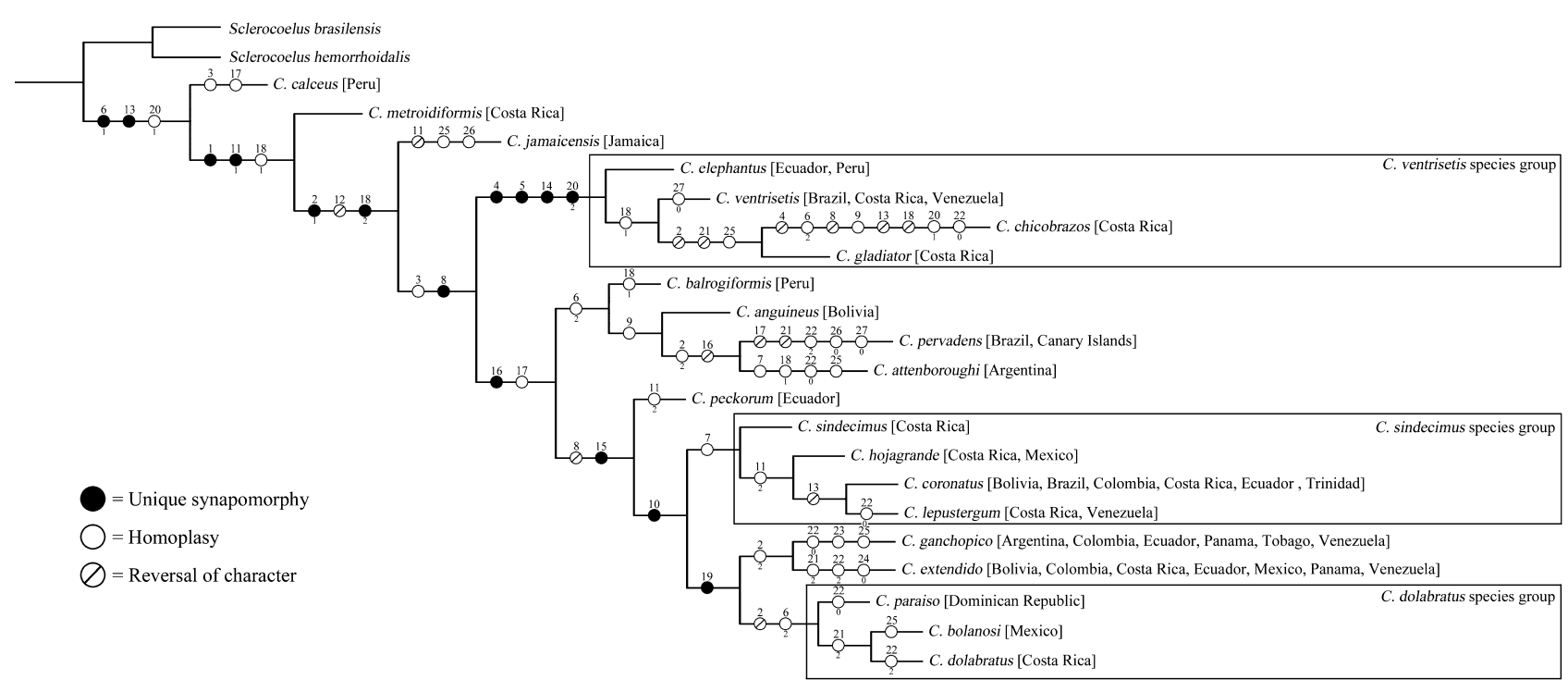

Fig. 27. Phylogeny of Chespiritos species based on the morphological features in Table 1. The cladogram was rooted by the two species of Sclerocoelus. Solid circles indicate unique and unreversed synapomorphies, empty circles indicate homoplasies and crossed circles indicate reversals. Ones and twos below the circles indicate multistate characters (unordered), zeroes below the circles indicate plesiomorphic characters.

General. Eye height $\sim 2.5 \times$ genal height. Mid femur with ventral row of 3 setae on proximal quarter. Distance between crossveins $\mathrm{dm}-\mathrm{cu}$ and $\mathrm{r}-\mathrm{m} \sim 2.0-2.5 \times$ length of dm-cu.

Male abdomen. S5 with a pair of large, apically incurved, long-setose posterolateral lobes, lobes connected via a membranous sheet with dense microtrichia; S5 medially short, length $\sim 0.20 \times$ width. Medial connecting sclerite elongate, slightly sinuate, posterior quarter swollen and slightly emarginate with a pair of lateral projections, each terminating in a strong seta. Epandrium uniformly longsetose. Cercus with a slight ventral indentation. Surstylus rectangular with a row of stout setae along anterior edge and a small patch of finer discal setae near the base; posterior edge sinuate, posteroapical corner with a distinct concave emargination; apex with a small, blade-like lobe. Postgonite dark, broad, sinuate along anterior margin, gradually broadened towards apex before abruptly narrowing about apical quarter posteriorly and apical eighth anteriorly (asymmetrical). Basiphallus large, rectangular; epiphallus small, square and directed posteriorly. Distiphallus with basal half large, heavily sclerotized and tubular, apical half semi-membranous with 2 stout sclerites supporting 3 scoop-like, laterally reticulated lobes which form a tube.

Female abdomen. T7 with 4 pairs of smaller setae and 1 pair of large posterolateral setae; width $\sim 1.5 \times$ that of T3; posteromedial notch semicircular, extending anteriorly $\sim 0.33 \times$ length of $\mathrm{T} 7$, posterior width $\sim 0.25 \times$ width of $\mathrm{T} 7$; anterolateral lobe large and rounded, angled anteriorly. T8 with 5 pairs of smaller setae; anterolateral lobe triangular and connected to $\mathrm{T} 8$, posterolateral lobe rectangular and separated from T8. Apical bulb of spermathecae stout and spherical, slightly less than length of smooth, elongate basal bulbs; apical bulb of single spermatheca grooved, apical bulbs of paired spermathecae smooth.

Type material. Holotype: COSTA RICA: Alajuela: Volcán Tenorio, Bijagua Biological Station, $700 \mathrm{~m}$, cut wet field, pans, 20.vi.2000, M. Buck, debu00132840 (ô, MNCR). Paratypes: COSTA RICA: Limón: Estrella Valley, Pandora, Malaise,

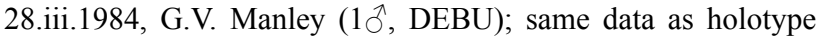
$\left(1 \jmath^{\lambda}, 2\right.$ ㅇ MNCR, DEBU).

Type locality. Costa Rica, Alajuela Province, Bijagua Biological Station.

Etymology. This name refers to the shapes of the surstylus and postgonite, each of which resembles a hatchet (Latin 'dolabratus': shaped like an axe).

Distribution. This species is known only from Costa Rica.

ACKNOWLEDGEMENTS. We would like to thank S. Paiero (School of Environmental Sciences, University of Guelph) for his help and insight during the development of this project, and Tiffany Yau (School of Environmental Sciences, University of Guelph) for advising the first author on techniques for biological illustration.

\section{REFERENCES}

Cumming J.M. \& Wood D.M. 2009: 2. Adult morphology and terminology. In Brown B.V., Borkent A., Cumming J.M., Wood D.M., Woodley N.E. \& Zumbado M.A. (eds): Manual of Central American Diptera. Vol. 1. NRC Research Press, Ottawa, pp. 9-50.

Goloboff P. \& Catalano S. 2016: TNT, version 1.5, with a full implementation of phylogenetic morphometrics. - Cladistics 32: $221-238$.

Goloboff P., Farris J. \& Nixon K. 2008: TNT, a free program for phylogenetic analysis. - Cladistics 24: 774-786.

Maddison W.P. \& Maddison D.R. 2018: Mesquite: A Modular System for Evolutionary Analysis. Version 3.6. URL: http:// www.mesquiteproject.org/. 
Marshall S.A. 1997: A revision of the Sclerocoelus galapagensis group (Diptera: Sphaeroceridae: Limosininae). — Insecta Mundi 11: 97-115.

Marshall S.A. 2000: Chespiritos, a new genus of Limosininae (Diptera: Sphaeroceridae) from Costa Rica. — Proc. Entomol. Soc. Wash. 102: 609-612.

Marshall S.A., RohÁček M., Dong H. \& Buck M. 2011: The state of Sphaeroceridae (Diptera: Acalyptratae): a world catalog update covering the years 2000-2010, with new generic synonymy, new combinations, and new distributions. - Acta Entomol. Mus. Nat. Pragae 51: 217-298.

Nixon K.C. 2002: Winclada. Version 1.61. Published by the author, Ithaca, NY, USA. URL: http://www.diversityoflife.org/ winclada/
Del Risco A.A., Del Risco A.E. \& Echeverri A. 2011: Oilbird (Steatornis caripensis), version 1.0. In Schulenberg T.S. (ed.): Neotropical Birds Online. Cornell Lab of Ornithology, Ithaca, NY, USA. URL: https://doi.org/10.2173/nb.oilbir1.01.

RoHÁČEK J. \& BucK M. 2003: Chespiritos pervadens spec. nov. (Diptera, Sphaeroceridae), a remarkable species with disjunct Neotropical-Macaronesian distribution. — Stud. Dipterol. 10: 43-50.

RoháčeK J., Marshall S.A., Norrbom A.L., Buck M., QuiRos D.I. \& Sмith I. 2001: World Catalog of Sphaeroceridae. Slezské Zemské Museum, Opava, 42 pp.

Received September 10, 2019; revised and accepted March 27, 2020 Published online April 20, 2020 